Article

\title{
New Biodegradable Poly(L-lactide)-Block- Poly(propylene adipate) Copolymer Microparticles for Long-Acting Injectables of Naltrexone Drug
}

\author{
Stavroula Nanaki ${ }^{1}$, Athina Viziridou ${ }^{2}{ }^{-}$, Alexandra Zamboulis ${ }^{1}$, Margaritis Kostoglou ${ }^{3}{ }^{(}$, \\ Georgios Z. Papageorgiou ${ }^{4}(\mathbb{D})$ and Dimitrios N. Bikiaris ${ }^{1, *(1)}$ \\ 1 Laboratory of Polymer Chemistry and Technology, Department of Chemistry, Aristotle University of \\ Thessaloniki, GR-541 24 Thessaloniki, Greece; sgnanaki@chem.auth.gr (S.N.); \\ azampouli@chem.auth.gr (A.Z.) \\ 2 Department of Food Science and Technology, International Hellenic University, GR-57400 Thessaloniki, \\ Greece; athina_viziridou@hotmail.com \\ 3 Laboratory of General and Inorganic Chemical Technology, Department of Chemistry, Aristotle University of \\ Thessaloniki, GR-541 24 Thessaloniki, Greece; kostoglu@chem.auth.gr \\ 4 Chemistry Department, University of Ioannina, P.O. Box 1186, 45110 Ioannina, Greece; gzpap@uoi.gr \\ * Correspondence: dbic@chem.auth.gr; Tel.: +30-2310-997812
}

Received: 18 March 2020; Accepted: 4 April 2020; Published: 7 April 2020

\begin{abstract}
In the present study, novel block copolymers of poly(L-lactide)-block-poly(propylene adipate) (PLLA-b-PPAd) were synthesized in two ratios, 90/10 and 75/25 $w / w$ and were further investigated as long-acting injectable (LAI) polymeric matrices in naltrexone base microparticle formulations. The synthesized polymers were characterized by ${ }^{1} \mathrm{H}-\mathrm{NMR},{ }^{13} \mathrm{C}-\mathrm{NMR}, \mathrm{FTIR}, \mathrm{XRD}$, TGA and DSC. NMR and FTIR spectroscopies confirmed the successful synthesis of copolymers while DSC showed that these are block copolymers with well-defined and separated blocks. Microparticles were prepared by single emulsification method and were further characterized. Nanoparticles in the range of $0.4-4.5 \mu \mathrm{m}$ were prepared as indicated by SEM, with copolymers giving the lowest particle size. By XRD and DSC it was found that naltrexone was present in the amorphous state in its microparticles. Dissolution study showed a drug release extending over seven days, indicating that these novel PLLA- $b$-PPAd copolymers could be promising matrices for naltrexone's LAI formulations. It was evidenced that drug release depended on the copolymer composition. Model release studies showed that drug release is controlled by diffusion.
\end{abstract}

Keywords: poly(L-lactide); poly(propylene adipate); amphiphilic block copolymers; naltrexone; drug encapsulation; microspheres; long-acting injectables; controlled release

\section{Introduction}

Aliphatic polyesters have proven to be a very promising class of biomaterials. Most importantly, these polyesters are regarded as readily biodegradable, due to the hydrolysable character of the ester bond and its accessibility (unlike aromatic polyesters). Additionally, aliphatic polyesters are generally biocompatible, due to the benign initial reagents (acids, hydroxy acids or diols), and to their biodegradation products which are water-soluble oligomers. Both initial monomers and degradation products are easily eliminated through urine cell activity [1]. As a result of their biodegradability and biocompatibility, another major advantage of aliphatic polyesters when it comes to drug delivery, is that there is no need for further surgical removal after drug exhaustion. Furthermore, aliphatic polyesters can easily be modified in order to tune the release of the encapsulated drug and achieve a desirable drug delivery profile [2]. Typical aliphatic polyesters that have already been studied 
as drug carriers are $\varepsilon$-polycaprolactone (PCL), poly(lactic acid) (PLA), poly(glycolic acid) (PGA), their copolymer poly(lactide-co-glycolide) (PLGA), which are typically prepared by ring-opening polymerizations, and polyesters resulting from the polycondensation of an aliphatic diol and an aliphatic dicarboxylic acid such as poly(ethylene succinate), poly(ethylene adipate), poly(propylene adipate) (PPAd). Among them, PLA is by far the most extensively studied. However, the use of PLA suffers from some limitations due to its high crystallinity and low hydrolysis rate. Copolymerization is an easy method to modulate the properties of a polymer, by varying the rigidity/flexibility of polymer chains, the hydrophilic/hydrophobic balance and the amorphous/crystalline ratio [3]. Copolymerization of PLA with more hydrophilic and amorphous polymers has been carried out to modify the required biomaterial properties for specific applications [4].

Naltrexone base (NTX) is a specific opioid antagonist, used in the treatment of both drug addiction and alcohol dependence. It is marketed in tablet form for oral administration but has some pharmacotherapeutic limitations (for example, a low oral bioavailability, as $98 \%$ of the drug is metabolized in the liver) and gastrointestinal side effects (nausea, abdominal pain, and vomiting). Treatment by oral administration of NTX requires a daily administration and its efficacy can be compromised due to the patient's non-compliance. Indeed, $37 \%$ of patients discontinue the daily oral use of NTX by 12 weeks and more than $80 \%$ discontinue its use by six months [5]. Currently there are two major types of sustained-release formulations for NTX delivery: (a) injectable depot formulations for long-acting release $\left(\right.$ Naltrel ${ }^{\circledR}$, Vivitrol ${ }^{\circledR}$, and Depotre $x^{\circledR}$ ), and (b) surgically implantable pellets (Prodetoxone $\AA$, Wedgewood $\AA$, and $\mathrm{O}^{\prime} \mathrm{Neil} 囚$ ) [6]. Regarding NTX implants, an early period (up to 12 months post-implant) of inflammation, foreign body reaction, and fibrosis has been reported, while the high cost of the implant limits its use [7]. Thus, novel drug delivery systems, such as microspheres and nanoparticles for long-acting injectables (LAI), that are able to be administered by parenteral route, are expected to improve NTX therapy. Indeed, such systems would allow the elimination of the first-pass metabolism, while providing a prolonged release. As a result, of the sustained prolonged release in LAI, a lower dosage could be achieved, thus reducing the toxic secondary effects. Finally, a single parenteral administration could tackle patient non-compliance issues.

Microparticle-formulations of NTX have already been reported, several of which involve PLA copolymers. For example, Akala et al. prepared and studied NTX-loaded poly(lactide-co-glycolide) (PLGA) microspheres [8]. The influence of the molar composition and the average molecular weight of the copolymers on the formation of nanospheres and the sustained release of NTX was studied. Depending on the formulation, release ranged from 30 to 150 days. Salehi et al. developed NTX-loaded micelles based on poly(N-isopropylacrylamide)-b-poly(L-lactide) copolymers [9]. It was shown that the increase of PLA resulted in a higher drug loading of the micelles, but also to a slower release ( 5 vs. $18 \%$ within the first $24 \mathrm{~h}$ ). Pagar et al. introduced $5 \mathrm{~mol} \%$ of a cyclic glycolic acid/leucine monomer (depsipeptide) to lactide polymerization to obtain a lactide-depsipeptide copolymer [10]. Microspheres loaded with NTX were formed employing a single emulsion solvent evaporation technique. NTX release studies showed an $82 \%$ release within 30 days. Nerantzaki et al. synthesized a series of castor oil, poly( $\varepsilon$-caprolactone) and poly(ethylene glycol) (PEG) block copolymers [11]. These copolymers were used as polymeric carriers for the fabrication of NTX-loaded microspheres by the single emulsion solvent evaporation technique, resulting in sustained release systems with drug release controlled by diffusion processes. Finally, similar PLGA-PEG-PLGA tri-block copolymers were also used as a delivery matrix, for the controlled release of naltrexone hydrochloride [12]. In vivo experiments showed that naltrexone half-life was successfully increased.

In the present study, novel poly(L-lactide)-block-poly(propylene adipate) copolymers, with two different mass compositions $(90 / 10$ and $75 / 25 w / w)$ were synthesized for the first time, as far as our knowledge goes. PLLA- $b$-PPAd copolymers were used as polymeric matrices for the nanoencapsulation of naltrexone drug, by the single emulsification method. The sustained release of NTX was studied, exhibiting a diffusion-controlled release mechanism. Finally, the experimental release studies were complemented by a theoretical modeling. 


\section{Materials and Methods}

\subsection{Materials}

Adipic acid (AdA) (purity: >99.5\%), poly(phosphoric acid) (PPA) and 1,3-propanediol (1,3-PD) (purity: $>99.6 \%$ ) were purchased from Fluka (Steinheim, Germany). Titanium butoxide (purity: $\left.>97.0 \%), \mathrm{Ti}(\mathrm{OBu})_{4}\right)$ and tin(II) 2-ethylhexanoate $\left(\mathrm{Sn}(\mathrm{Oct})_{2}\right)$ were used as catalysts, L-Lactide (LA), (3S)-cis-3,6-Dimethyl-1,4-dioxane-2,5-dione (98\%) and poly(vinyl alcohol) (PVA), $M_{\mathrm{W}}$ 31,000-50,000 $\mathrm{Da}$ (87\%-89\% hydrolyzed) were purchased from Sigma Aldrich Chemical Co (Steinheim, Germany). Rhizopus oryzae and Pseudomonas cepacia were purchased from BioChemika (Steinheim, Germany). Naltrexone base (99.9\%) was kindly donated by Pharmathen S.A. (Athens, Greece). All other reagents and solvents used for the analytical methods were of analytical grade.

\subsection{Synthesis of Aliphatic Polyesters}

\subsubsection{Synthesis of Poly(Propylene Adipate) (PPAd) Aliphatic Polyester}

The classic two-stage melt polycondensation method was used for the synthesis of PPAd aliphatic polyesters [13,14]. In the first stage (esterification), adipic acid (AdA) and 1,3-propanediol (1,3-PD), in a 1/1.2 molar ratio were charged into the reaction tube in the presence of $400 \mathrm{ppm}$ of $\operatorname{Ti}(\mathrm{OBu})_{4}$. The reaction mixture was heated at $180{ }^{\circ} \mathrm{C}$, in a nitrogen atmosphere, under continuous stirring. The reaction lasted until the theoretical amount of $\mathrm{H}_{2} \mathrm{O}$ produced during the reaction was collected. In the second stage (polycondensation), poly(phosphoric acid) PPA was added (5 $\times 10^{-4}$ mol of $\mathrm{PPA} / \mathrm{mol} \mathrm{AdA}$ ) and vacuum (5.0 Pa) was slowly applied to reduce the creation of foam and the risk of poly(propylene adipate) oligomer sublimation. Polycondensation procedure was carried out at $240{ }^{\circ} \mathrm{C}$ for $2 \mathrm{~h}$.

\subsubsection{Synthesis of Poly(L-Lactide)-b-Poly(Propylene Adipate) Copolymers}

PLLA- $b$-PPAd copolymers, in 90/10 and 75/25 mass ratios, were synthesized by ring-opening polymerization of lactide. Proper amounts of LA and PPAd polyester were inserted into the reaction tube and a toluene solution of $\mathrm{Sn}(\mathrm{Oct})_{2}$ was added $(400 \mathrm{ppm})$. Ring-opening polymerization took place at $220^{\circ} \mathrm{C}$, under nitrogen flow, for $60 \mathrm{~min}$, while the stirring rate was kept stable at $500 \mathrm{rpm}$. At the end of the polymerization, unreacted LA monomer was removed by sublimation by slowly applying vacuum $(\approx 5 \mathrm{~Pa})$ over a period of $15 \mathrm{~min}$, to avoid excessive foaming. The synthesized polyesters were further purified by dissolution in chloroform and precipitation with cold methanol.

\subsection{Polymer Characterization}

\subsubsection{Intrinsic Viscosity}

Intrinsic viscosity, $[\eta]$, measurements were performed with an Ubbelohde viscometer (Schott Gerate GMBH, Hofheim, Germany) at $25^{\circ} \mathrm{C}$. All polyesters were dissolved in chloroform $(1 \% w / v)$ at room temperature and filtered through a $0.2 \mathrm{~mm}$ Teflon filter. The intrinsic viscosity was calculated using Equation (1) [15]:

$$
[\eta]=\frac{\left[2\left\{\frac{t}{t_{0}}-\ln \left(\frac{t}{t_{0}}\right)-1\right\}\right]^{\frac{1}{2}}}{c}
$$

where $c=$ concentration of the solution, $t=$ flow time of the polymer solution and $t_{0}=$ flow time of pure solvent $\left(\mathrm{CHCl}_{3}\right)$.

\subsubsection{Gel Permeation Chromatography (GPC)}

Molecular weight determinations were performed by gel permeation chromatography (GPC) using a high temperature GPC system, Waters model 600, equipped with Shimadzu RID-10A (Milford, 
MA, USA) refractive index detector and columns Water Styragels (Milford, MA, USA) in the order HR5, HR4, HR3, HR2, HR1, $10 \mathrm{mg} / 700 \mu \mathrm{L}$ sample concentration, and a $200 \mu \mathrm{L}$ injection volume. Tetrahydrofuran (THF) was used as the eluent $(1 \mathrm{~mL} / \mathrm{min})$ and the measurements were performed at $35^{\circ} \mathrm{C}$. Calibration was performed using 9 polystyrene standards with $1000-300,000$ molecular weight distribution.

\subsubsection{Nuclear Magnetic Resonance $\left({ }^{1} \mathrm{H}-\mathrm{NMR},{ }^{13} \mathrm{C}-\mathrm{NMR}\right)$}

NMR spectra were recorded in deuterated chloroform $\left(\mathrm{CDCl}_{3}\right)$, on an Agilent 500 spectrometer (Agilent Technologies, Santa Clara, CA, USA), at room temperature. Spectra were internally referenced with tetramethylsilane (TMS) and calibrated using the residual solvent peak.

\subsubsection{X-ray Powder Diffraction (XRD)}

X-ray powder diffraction (XRD) patterns of neat PLLA, PPAd, and their copolymers were recorded using a MiniFlex II diffractometer (Rigaku, model MiniFlex 600, Chalgrove, Oxford, UK), with Bragg-Brentano geometry $(\theta, 2 \theta)$ and a Ni-filtered $\mathrm{Cu} K$ radiation $(\lambda=0.154 \mathrm{~nm})$. The samples were scanned from $5^{\circ}$ to $55^{\circ} 2 \theta$.

\subsubsection{Fourier Transform-Infrared Spectroscopy (FTIR)}

FTIR spectra were obtained using a Perkin Elmer FTIR spectrometer, model Spectrum 1000 (Perkin Elmer, Waltham, MA, USA). In order to collect the spectra, a small amount of polymer was grinded with $\mathrm{KBr}(1 \mathrm{wt} \%)$ and compressed to form tablets. The IR spectra of these tablets, in absorbance mode, were obtained in the spectral region of $450-4000 \mathrm{~cm}^{-1}$ using a resolution of $4 \mathrm{~cm}^{-1}$ and 24 co-added scans.

\subsubsection{Differential scanning calorimetry (DSC)}

Differential scanning calorimetry (DSC) was performed using model DSC Q2000 (TA Instruments, Eschborn, Germany). Samples of $5 \pm 0.1 \mathrm{mg}$ were sealed in aluminum caps and heated $50{ }^{\circ} \mathrm{C}$ above their melting point, at a $20^{\circ} \mathrm{C} / \mathrm{min}$ heating rate, under nitrogen atmosphere. The samples were held at that temperature for $5 \mathrm{~min}$ in order to erase any thermal history and then cooled to $-85^{\circ} \mathrm{C}$ (cooling rate $250^{\circ} \mathrm{C} / \mathrm{min}$ ) in order to prevent crystallization. The samples were heated again using the same conditions. $T_{\mathrm{g}}, T_{\mathrm{m}}$, and heat of fusion were recorded from the second scan.

\subsubsection{Thermogravimetric Analysis (TGA)}

The thermogravimetric analysis was performed using the Setaram Setsys TG-DTA 16/18 instrument (Setaram instrumentation, Lyon, France). Samples of neat PPAd, PLLA and PLLA/PPAd copolymers, weighed $6.0 \pm 0.2 \mathrm{mg}$, were placed in aluminum crucibles. A blank aluminum crucible was used as a reference. The samples were heated from ambient temperature to $550{ }^{\circ} \mathrm{C}$, with a constant flow rate of $50 \mathrm{~mL} / \mathrm{min}$ nitrogen at rates of $10^{\circ} \mathrm{C} / \mathrm{min}$.

\subsubsection{Enzymatic Hydrolysis Study}

Films of neat PLLA, PPAd and PLA/PPAd copolymers were prepared $\left(5 \times 5 \mathrm{~cm}^{2}\right.$ and $5 \mathrm{~mm}$ thickness) with a PW 30 Otto Weber hydraulic press (Paul-Otto Weber GmbH, Remshalden, Germany) connected to a temperature controller (Omron E5AX). The samples were incubated at $37 \pm 1{ }^{\circ} \mathrm{C}$ for 20 days in Petri dishes containing phosphate buffered saline (PBS) $(\mathrm{pH}=7.4)$ with Rhizopus oryzae and Pseudomonas Cepacia lipases at 0.09 and $0.01 \mathrm{mg} / \mathrm{mL}$ concentrations respectively. After specific period intervals, films were removed from the Petri dishes, washed with distilled water and weighed till constant weight. The degree of biodegradation was estimated by mass loss of pre-weighed samples. 
Weight loss percentage of the polyester films was obtained according to the following equation:

$$
\text { Weight loss }(\%)=\frac{\left(W_{0}-W_{r}\right)}{W_{0}} \times 100 \%
$$

where $W_{0}$ is the weight of the specimens before degradation, $W_{r}$ the weight of the specimens after degradation and drying.

\subsubsection{Scanning Electron Microscopy (SEM)}

SEM (JSM-6390LV, JEOL Company, Peabody, MA, USA) was used to evaluate the morphology of the prepared films prior and after enzymatic hydrolysis. Carbon coating was used to cover the obtained films (improvement in the conductivity of the electron beam), while the accelerating voltage, the probe current, and the counting time were set at $20 \mathrm{kV}, 45 \mathrm{nA}$, and $60 \mathrm{~s}$, respectively.

\subsection{Microparticles Formulation}

\subsubsection{Preparation of PLLA- $b$-PPAd Microparticles}

An oil-in-water $(\mathrm{O} / \mathrm{W})$ emulsification technique was used for NTX microencapsulation in polyester matrices. Briefly, $150 \mathrm{mg}$ of polymer and $50 \mathrm{mg}$ of NTX were dissolved in $10 \mathrm{~mL}$ of dichloromethane (DCM). The resultant solution was added dropwise in $50 \mathrm{~mL}$ of a $1 \% w / v$ PVA aqueous solution. Homogenization was performed with a rotor stator stirrer (Ultra Turax IKA T18 basic, Staufen, Germany) for $2 \mathrm{~min}$ at 24,000 rpm. The homogenous dispersion was then transferred to $100 \mathrm{~mL}$ of deionized water, homogenized for $1 \mathrm{~min}$ using a rotor stirrer and left overnight under magnetic stirring till total evaporation of DCM. The formed microspheres were collected via centrifugation at $9000 \mathrm{rpm}$ for $20 \mathrm{~min}$ (Thermo Electron Corporation, Model Heraeus Pico 17 Centrifuge), and washed three times with deionized water in order to remove the remaining quantities of PVA. Microparticles were isolated by freeze drying.

\subsubsection{Characterization of Microparticles}

\subsubsection{In Vitro Release Profile}

Dissolution studies were conducted using United States Pharmacopeia I basket method (50 rpm, $37^{\circ} \mathrm{C}$, and $500 \mathrm{~mL}$ dissolution medium). NTX-loaded microspheres suspensions corresponding to $50 \mathrm{mg}$ of drug were placed in a dialysis cellulose membrane bag (D9402-100FT; Sigma-Aldrich, Steinheim, Germany) with molecular weight cut-off $12,000-14,000$, placed into the baskets, and transferred to $500 \mathrm{~mL}$ phosphate buffer ( $\mathrm{pH} 7.4)$ containing $0.5 \mathrm{~mL}$ Tween 20. Samples $(2 \mathrm{~mL})$ were withdrawn at predetermined intervals and filtered through $0.45 \mu \mathrm{m}$ filters. The samples were analyzed by HPLC as described beneath (Section 2.4.2.2). The percentage yield, drug loading, and drug entrapment efficiency of microspheres were calculated according to the following equations:

$$
\begin{gathered}
\text { Yield of microparticles }(\%)=\frac{(\text { weight of microparticles })}{(\text { weight of polymer and drug fed initially })} \times 100 \\
\text { Drug loading }(\%)=\frac{(\text { weight of drug in microparticles })}{(\text { weight of microparticles })} \times 100 \\
\text { Entrapment efficiency }(\%)=\frac{(\text { weight of drug in microparticles })}{(\text { weight of initially used drug })} \times 100
\end{gathered}
$$

\subsubsection{HPLC Analysis}

Quantitative analysis was performed using a Shimadzu high pressure liquid chromatography (HPLC) prominence system consisting of a degasser (Model DGU-20A5, Tokyo, Japan), a liquid 
chromatograph, an auto sampler, a diode array detector and a thermostatic oven. A modified, previously validated, method was used for the analysis [9]. The chromatograms were obtained and processed with the LC solutions software v. 1.21 SP1. In detail, an Athena CNW Technology $\mathrm{C} 18,\left(250 \times 4.6 \mathrm{~mm}\right.$ and $5 \mu \mathrm{m}$ internal diameter) at column temperature of $40{ }^{\circ} \mathrm{C}$ chromatographic workstation (CSW) was used for regression analysis and data acquisition. Flow rate was $1 \mathrm{~mL} / \mathrm{min}$ and the injection volume were $20 \mu \mathrm{L}$. Mobile phase was phosphate buffer $(10 \mathrm{mM}, \mathrm{pH}$ was adjusted to 3.5 using $\left.\mathrm{H}_{3} \mathrm{PO}_{4}\right) / \mathrm{ACN} 80 / 20 v / v$. Each sample was measured in triplicate.

\section{Results and Discussion}

\subsection{Synthesis and Characterization of Block Copolymers}

PLLA- $b$-PPAd copolymers were synthesized by a combination of melt polycondensation and ring-opening polymerization, as described in Figure 1. Initially, poly(propylene adipate) (PPAd) homopolymer was synthesized by a two-stage melt polycondensation method [16,17]. Briefly, during esterification (1st stage), PPAd oligomers were synthesized and water was removed as a byproduct. During polycondensation (2nd stage), the temperature was increased to $240{ }^{\circ} \mathrm{C}$ and reduced pressure was applied in order to build up the molecular weight of the polyester. Water and 1,3-propanediol byproducts were removed by distillation in a graduated cylinder. 1,3-propanediol was added in small excess ensuring that most of the prepared macromolecules acquired hydroxyl end groups. It is necessary to have hydroxyl-terminated macromolecules, as these will act as initiators for the ring-opening polymerization of lactide and carboxylic acid groups cannot initiate this polymerization.

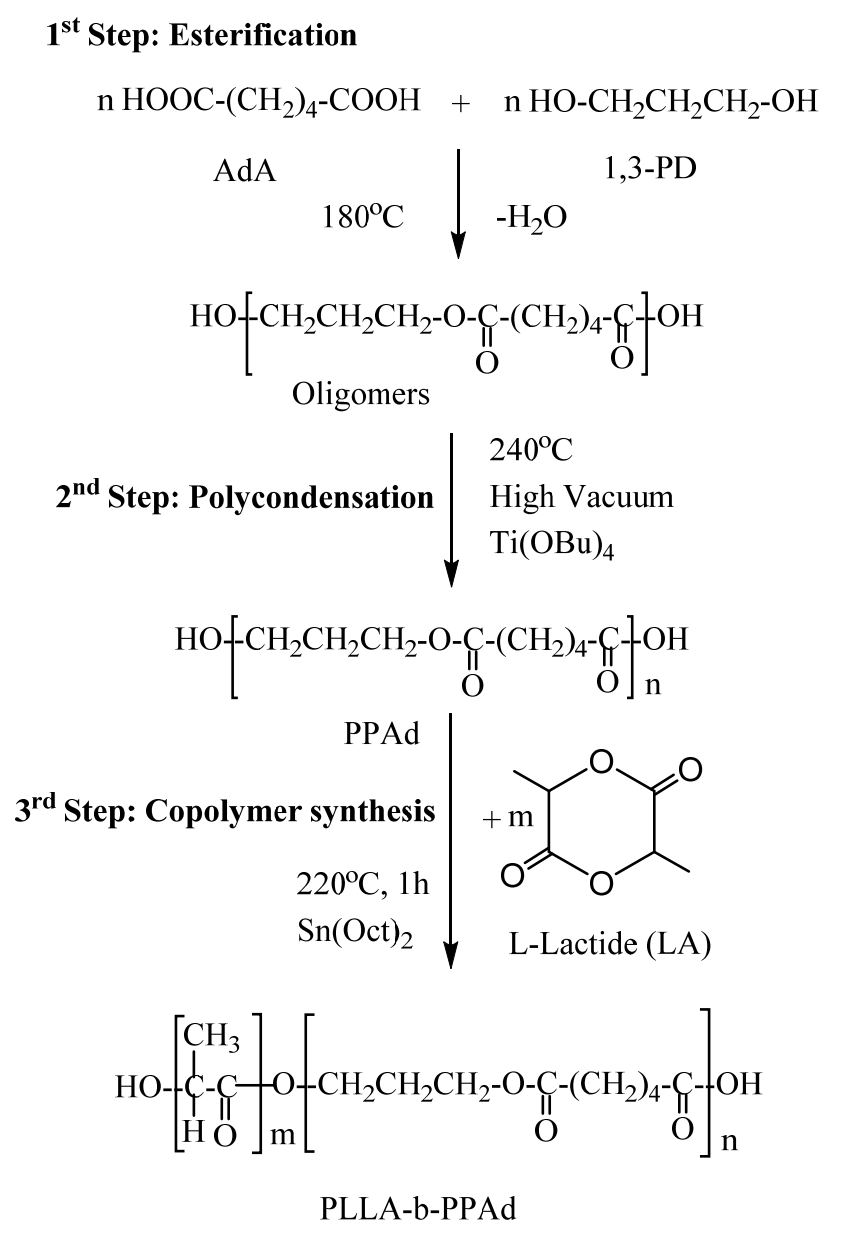

Figure 1. Synthesis of poly(L-lactide)- $b$-poly(propylene adipate) copolymers. 
The copolymerization between PLLA and PPAd was carried out at $220{ }^{\circ} \mathrm{C}$ in the presence of stannous octoate $\left(\mathrm{Sn}(\mathrm{Oct})_{2}\right)$, by ring-opening polymerization of LA, using the prepared PPAd homopolymer as a macroinitiator. After $1 \mathrm{~h}$ at atmospheric pressure, vacuum was applied ( $\approx 5 \mathrm{~Pa})$ for $15 \mathrm{~min}$ to remove any unreacted LA. PLLA- $b$-PPAd copolymers, containing 10 and $25 \mathrm{wt} \%$ of PPAd were thus synthesized (Figure 1).

Characterization of the synthesized PPAd polyester by GPC measurements showed an average number molecular weight of $35,000 \mathrm{~g} / \mathrm{mol}$ and an average weight molecular weight of 50,700 g/mol. The corresponding values for PLLA were $86,000 \mathrm{~g} / \mathrm{mol}$ and $133,900 \mathrm{~g} / \mathrm{mol}$, respectively, while for the copolymers the recorded molecular weights ranged between $47,700-53,700 \mathrm{~g} / \mathrm{mol}$, as detailed in Table 1 . Intrinsic viscosities of PLLA and PPAd were found to be 0.99 and $0.38 \mathrm{dL} / \mathrm{g}$ respectively while the values for the copolymers ranged between $0.65-0.77 \mathrm{dL} / \mathrm{g}$. It was observed that as the percentage of PPAd increased, the intrinsic viscosity decreased. In other words, the addition of PPAd led to a decrease in the molecular weight of the formed copolymers. This was expected since the LA amount for the preparation of copolymers was reduced and thus shorter chains were obtained. All samples exhibited unimodal distribution in GPC, i.e., only a single broad peak appeared (Figure 2), with no oligomers being detected. In addition, the low polydispersity index (PDI) values indicate that no transesterification and/or backbiting reactions occurred during the copolymerization [18].

Table 1. Theoretical and calculated compositions, intrinsic viscosities, and molecular weights of the prepared polymers.

\begin{tabular}{ccccccccc}
\hline Samples & $\begin{array}{c}\boldsymbol{w} / \boldsymbol{w} \\
\text { Ratio }\end{array}$ & $\begin{array}{c}\mathbf{1}^{\mathbf{1}} \mathbf{H} \text { NMR } \\
(\mathbf{m o l} \text { Ratio) }\end{array}$ & $\begin{array}{c}\text { Exp. } \\
\boldsymbol{w} / \boldsymbol{w} \\
\text { Ratio }^{\mathbf{a}}\end{array}$ & $\begin{array}{c}{[\eta \mathbf{}]} \\
(\mathbf{d L} / \mathbf{g})\end{array}$ & $\begin{array}{c}\text { Average } \\
\boldsymbol{M}_{\mathbf{n}} \\
(\mathbf{g} / \mathbf{m o l})\end{array}$ & $\begin{array}{c}\text { Average } \\
\boldsymbol{M}_{\mathbf{w}} \\
(\mathbf{g} / \mathbf{m o l})\end{array}$ & $\boldsymbol{M}_{\mathbf{w}} / \boldsymbol{M}_{\mathbf{n}}$ & $\boldsymbol{X}_{\mathbf{c}}(\mathbf{\%})$ \\
\hline PLLA & $100 / 0$ & $100 / 0$ & $100 / 0$ & 0.99 & 86,000 & 133,900 & 1.56 & 50.6 \\
PLLA/PPAd 90/10 & $90 / 10$ & $88 / 12$ & $85 / 15$ & 0.77 & 53,700 & 79,500 & 1.48 & 18.5 \\
PLLA/PPAd 75/25 & $75 / 25$ & $74 / 26$ & $69 / 31$ & 0.65 & 47,700 & 77,400 & 1.62 & 13.5 \\
PPAd & $0 / 100$ & $0 / 100$ & $0 / 100$ & 0.38 & 35,000 & 50,700 & 1.45 & 26.0 \\
\hline
\end{tabular}

${ }^{a}$ : experimental ratio calculated from the mol ratios, as calculated from ${ }^{1} \mathrm{H}-\mathrm{NMR}$ spectra.

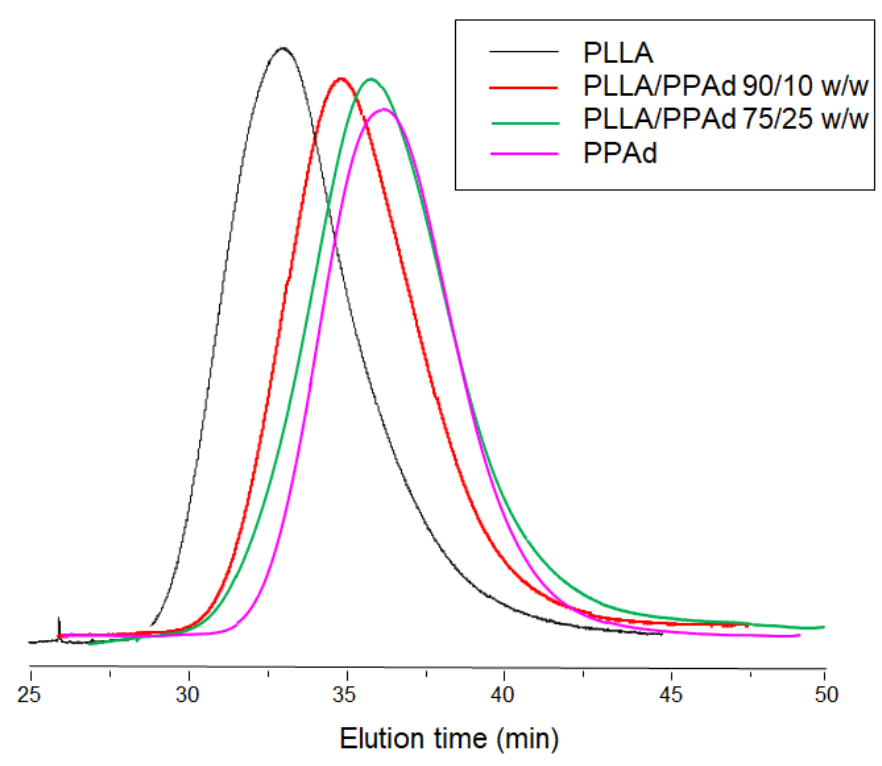

Figure 2. Gel permeation chromatography of poly(L-lactide) (PLLA), poly(propylene adipate) (PPAd) and PLLA- $b$-PPAd copolymers. 
In order to evaluate the successful synthesis of the copolymers, NMR spectra were recorded. The ${ }^{1} \mathrm{H}-\mathrm{NMR}$ spectra of PLLA, PPAd, and PLLA- $b$-PPAd copolymers are shown in Figure 3A. The ${ }^{1} \mathrm{H}-\mathrm{NMR}$ spectrum of PPAd, exhibits a triple peak at $4.15 \mathrm{ppm}$ corresponding to methylene group $d$, a quintuple peak at $1.97 \mathrm{ppm}$ corresponding to methylene group $e$, a single peak at $2.33 \mathrm{ppm}$ owing to methylene group $b$ and a multiple peak at $1.66 \mathrm{ppm}$ attributed to methylene group $c$. These peaks have also been documented in previous studies [16,17]. Typical resonance signals were obtained for PLLA, i.e., a quadruple peak at $5.17 \mathrm{ppm}$ attributed to methine group $h$, and a double peak at $1.6 \mathrm{ppm}$ corresponding to methyl group $g$. These peaks are in accordance with the literature $[19,20]$.
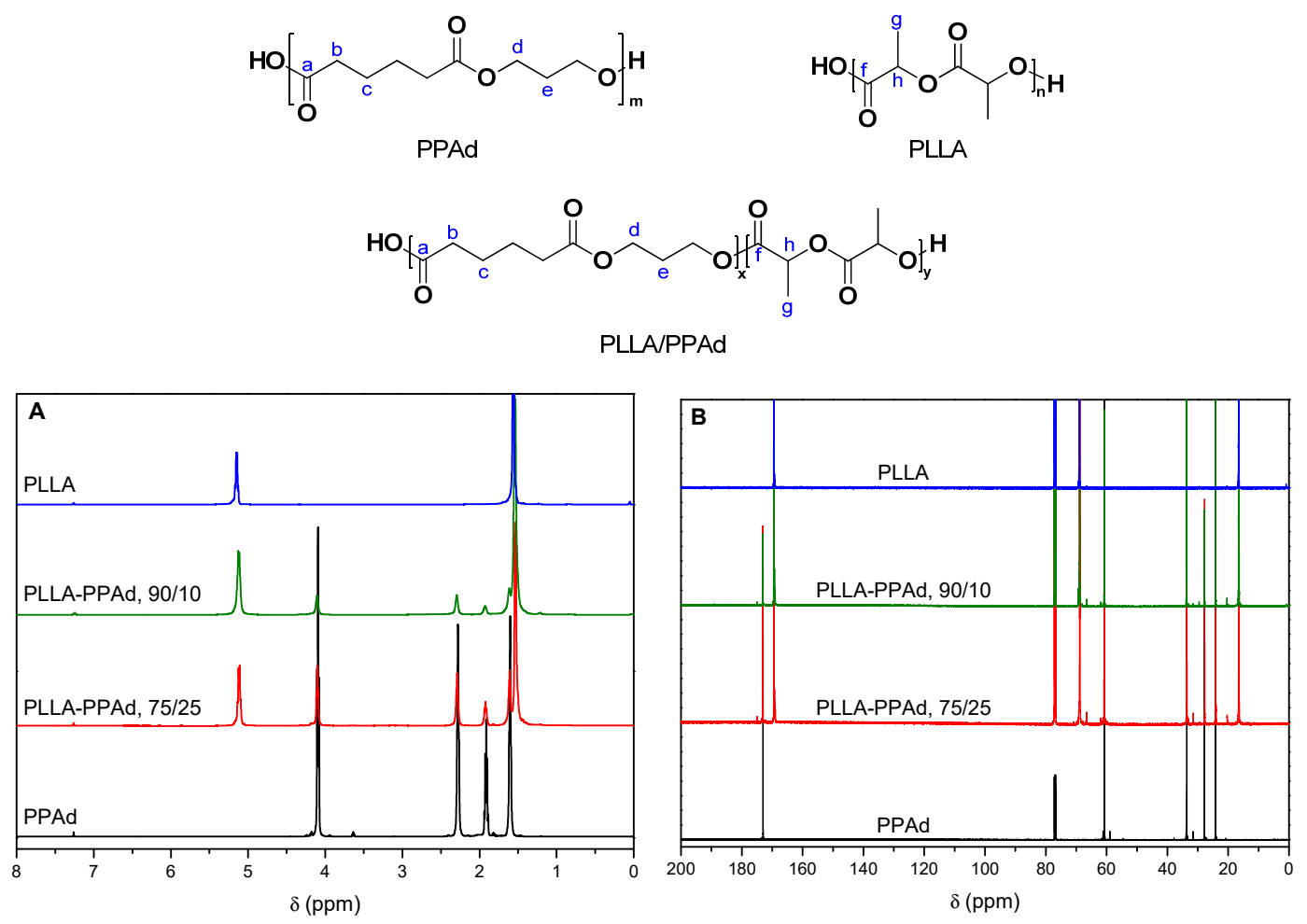

Figure 3. (A) ${ }^{1} \mathrm{H}-\mathrm{NMR}$ and (B) ${ }^{13} \mathrm{C}-\mathrm{NMR}$ spectra of PLLA, PLLA-b-PPAd copolymers and PPAd.

${ }^{1} \mathrm{H}-\mathrm{NMR}$ spectra of copolymers were similar for all the copolymers synthesized, and exhibited the characteristic resonance signals of both PLLA and PPAd: methylene protons $b$ and $c$ at 2.29 and $1.62 \mathrm{ppm}$ respectively, methylene protons $d$ and $e$ at 4.11 and $1.93 \mathrm{ppm}$ respectively (PPAd segment) and methine and methyl protons $h$ and $g$ at 5.13 and $1.54 \mathrm{ppm}$ respectively (PLLA segment). In the spectra of PPAd, the peak at $3.65 \mathrm{ppm}$ is attributed to the protons $d^{\prime}$ which are adjacent to the hydroxyl end-group of PPAd chains. During the polymerization, PPAd chains initiate the ring-opening polymerization of lactide via the $\mathrm{OH}$-terminated end. The disappearance of this peak in the spectra of the PLLA-PPAd copolymers indicates the successful polymerization and the formation of block copolymers. The molar composition of the copolymers was calculated by ${ }^{1} \mathrm{H}-\mathrm{NMR}$ spectra comparing the integrations of the $\mathrm{CH}(h)$ group of the PLA unit and the $\mathrm{CH}_{2}(e)$ group of PPAd. For both copolymers, a better incorporation of PPAd units in the copolymers was observed (15 and $31 \mathrm{wt} \%$ instead of 10 and $25 \mathrm{wt} \%$ ). This could be attributed to some lactide sublimation, due to the high temperature of polymerization. All results are presented in Table 1 .

In the ${ }^{13} \mathrm{C}$ spectrum (Figure 3B), the carbonyl bond of the ester groups are observed at $169.5 \mathrm{ppm}$ $(\mathrm{C}=\mathrm{O}(f), \mathrm{PLLA})$ and $173.1 \mathrm{ppm}\left(\mathrm{C}=\mathrm{O}(a)\right.$, PPAd). Peaks at $24.2\left(\mathrm{CH}_{2}(c)\right), 27.8\left(\mathrm{CH}_{2}(e)\right), 33.7\left(\mathrm{CH}_{2}(b)\right)$ and $60.8 \mathrm{ppm}\left(\mathrm{CH}_{2}(d)\right)$ are attributed to the PPAd unit, while the peaks at $16.6\left(\mathrm{CH}_{2}(g)\right)$ and $68.9 \mathrm{ppm}$ $\left(\mathrm{CH}_{2}(h)\right)$ are attributed to the PLLA unit. Similarly to the ${ }^{1} \mathrm{H}-\mathrm{NMR}$ spectra, the disappearance of the peak around $58.9 \mathrm{ppm}$ indicates that PPAd chains react via the $\mathrm{OH}$-terminated end. The absence of 
peaks between the two carbonyl ${ }^{13} \mathrm{C}$ resonance signals further corroborates that block and not random copolymers were obtained.

The formation of copolymers was also confirmed with FTIR spectroscopy. Figure 4 shows the FTIR spectra of neat PLLA, PPAd and their copolymers. PLLA spectra exhibits a broad absorption peak in the range $3700-3600 \mathrm{~cm}^{-1}$ which is assigned to $v(\mathrm{O}-\mathrm{H})$ vibration modes. Hydrogen association can easily occur in hydroxyl groups, resulting in a shift of the corresponding absorption peak to lower wavenumbers and a gradual widening with the increase of the association degree [21]. Furthermore, the two peaks at about 2951 and $3003 \mathrm{~cm}^{-1}$ correspond to the $v(\mathrm{C}-\mathrm{H})$ vibration modes of methyl groups. Besides, the $\delta(\mathrm{C}-\mathrm{H})$ modes of methyl appear around 1458 and $1362 \mathrm{~cm}^{-1}$. In the $v(\mathrm{C}=\mathrm{O}), v(\mathrm{C}-\mathrm{O})$ and $v(C-C)$ regions, PLLA exhibits sharp absorption peaks at 1760, 1081, and $1192 \mathrm{~cm}^{-1}$ respectively. PPAd exhibits a peak at $3000-2900 \mathrm{~cm}^{-1}$ corresponding to the $v(\mathrm{C}-\mathrm{H})$ vibration modes of the methylene groups and sharp absorption peaks at 1731, 1254, and $1192 \mathrm{~cm}^{-1}$ corresponding to $v(C=O), v(C-O)$ and $v(C-C)$ respectively. No significant absorption was observed around $3400-3700 \mathrm{~cm}^{-1}$, confirming a reasonably high polymerization degree. The main peaks appearing in the homopolymer spectra are retained in the copolymer spectra, without the appearance of any new peaks. These spectra exhibit sharp peaks between 1730 and $1775 \mathrm{~cm}^{-1}$ due to vibration of the different ester bonds $v(C=O)$ and wider peaks at $1200-1100 \mathrm{~cm}^{-1}$ attributed to the $v(\mathrm{C}-\mathrm{O})$ bond, indicating that copolymer formation has taken place [22].

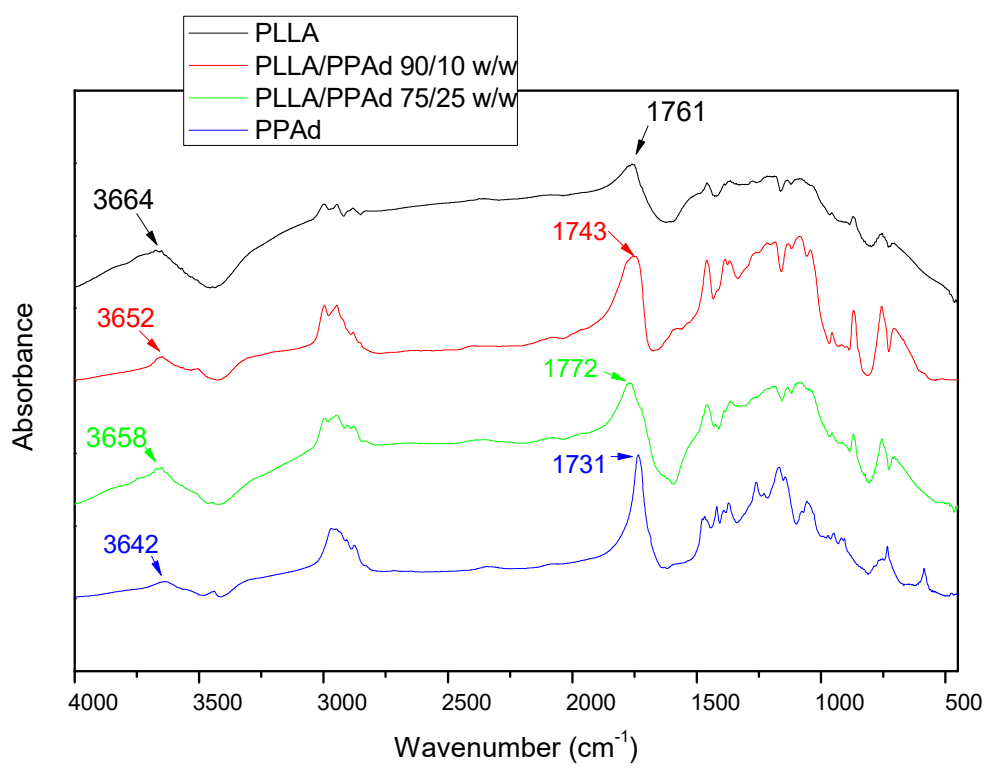

Figure 4. FTIR spectrum of all synthesized polyesters.

The physical state of the prepared copolymers is very crucial for drug release and was studied by $X R D$ and DSC. Figure 5 shows the $X$-ray diffraction patterns for the synthesized polyesters. Neat PLLA is a polymer with a high degree of crystallinity with characteristic peaks at $2 \theta=17.20,19.60,22.81$ and $31.60^{\circ}$. PPAd shows broad peaks at $2 \theta=17.91,19.90,22.01,23.20,25.40$ and $30.50^{\circ}$ with low intensity, thus exhibiting a lower degree of crystallinity. Concerning the copolymers, only a small peak at $2 \theta=17.20^{\circ}$ appears, indicating that the synthesized copolymers have a reduced crystallinity compared to both homopolymers. 


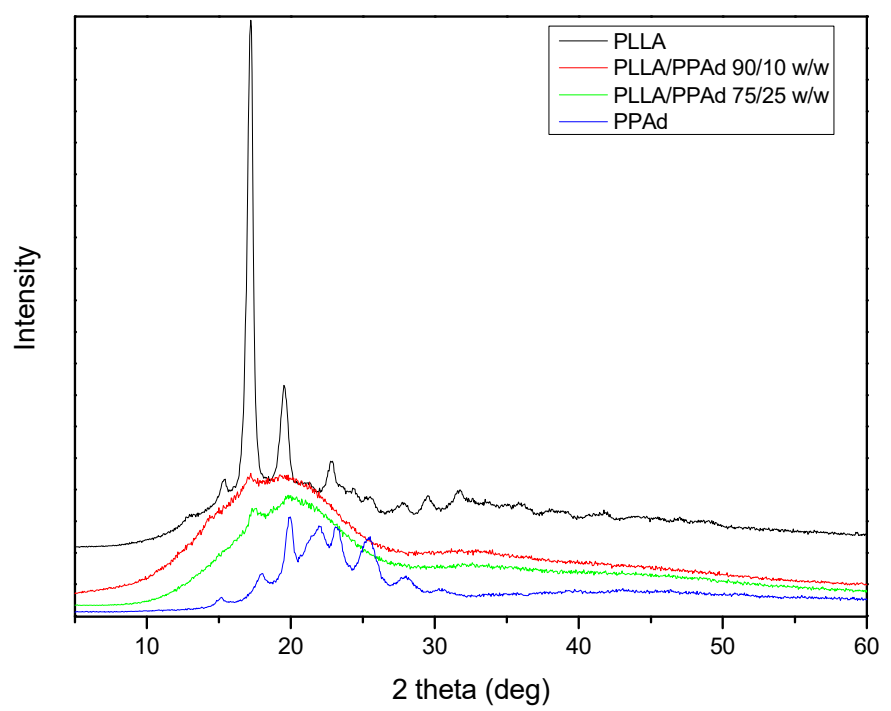

Figure 5. X-ray diffraction patterns of the synthesized polyesters.

The degree of crystallinity of all samples was calculated by wide angle X-ray diffraction patterns using the relative areas under the crystalline peaks $\left(A_{\mathrm{c}}\right)$ and the amorphous background $\left(A_{\mathrm{am}}\right)$ using Equation (6), according to Lu and Hay [23], and are summarized in Table 1. As expected, PLLA showed the highest degree of crystallinity, with a value equal to $50.6 \%$. In the copolymers the degree of crystallinity decreased with increasing PPAd content. This was expected since PPAd has a low degree of crystallinity (26\%) and its incorporation into the macromolecular chains hinders the crystallization of PLLA. Consequently, the copolymer with the highest PPAd amount $(25 \mathrm{wt} \%)$ has the lowest degree of crystallinity.

$$
X_{c}=\left(1-\frac{A_{a m}}{A_{c}}\right)^{-1}
$$

The thermal properties of all prepared polyesters were also studied. PPAd and PLLA are semicrystalline materials, which showed $T_{\mathrm{g}}$ values at 59.4 and $-53{ }^{\circ} \mathrm{C}$, and $T_{\mathrm{m}}$ values at 151.6 and $49.1{ }^{\circ} \mathrm{C}$, respectively (Figure $6 \mathrm{~A}$ ). The copolymer with $10 \mathrm{wt} \%$ PPAd exhibits also a single $T_{\mathrm{g}}$ at $50.5^{\circ} \mathrm{C}$, which is very close to that of neat PLLA. On the other hand, copolymer PLLA/PPAd 75/25 $w / w$ has two glass transition temperatures at $-51{ }^{\circ} \mathrm{C}$ and $35.8^{\circ} \mathrm{C}$ (Table 2). The former corresponds to the PPAd sequences and the latter to the PLLA sequences. This is in good agreement with the literature. Indeed, for a block copolymer consisting of two heterogeneous phases, two glass transition temperatures corresponding to those of the homopolymers are expected [24]. Two $T_{\mathrm{g}}$ values should also have been recorded for the copolymer with $10 \mathrm{wt} \%$ of PPAd. However, since the length of the PLLA segment is expected to be much higher than that of the PPAd segment, the $T_{\mathrm{g}}$ of PPAd is difficult to be observed. The highly amorphous character of these copolymers, as already suggested from XRD studies, was also confirmed by the appearance of a cold crystallization peak at $10{ }^{\circ} \mathrm{C}$ and $89.9{ }^{\circ} \mathrm{C}$ for polyesters containing 10 and $25 \mathrm{wt} \%$ PPAd, respectively. The recorded $T_{\mathrm{m}}$ values of PLLA sequence were at 150.6 and $149^{\circ} \mathrm{C}$. 

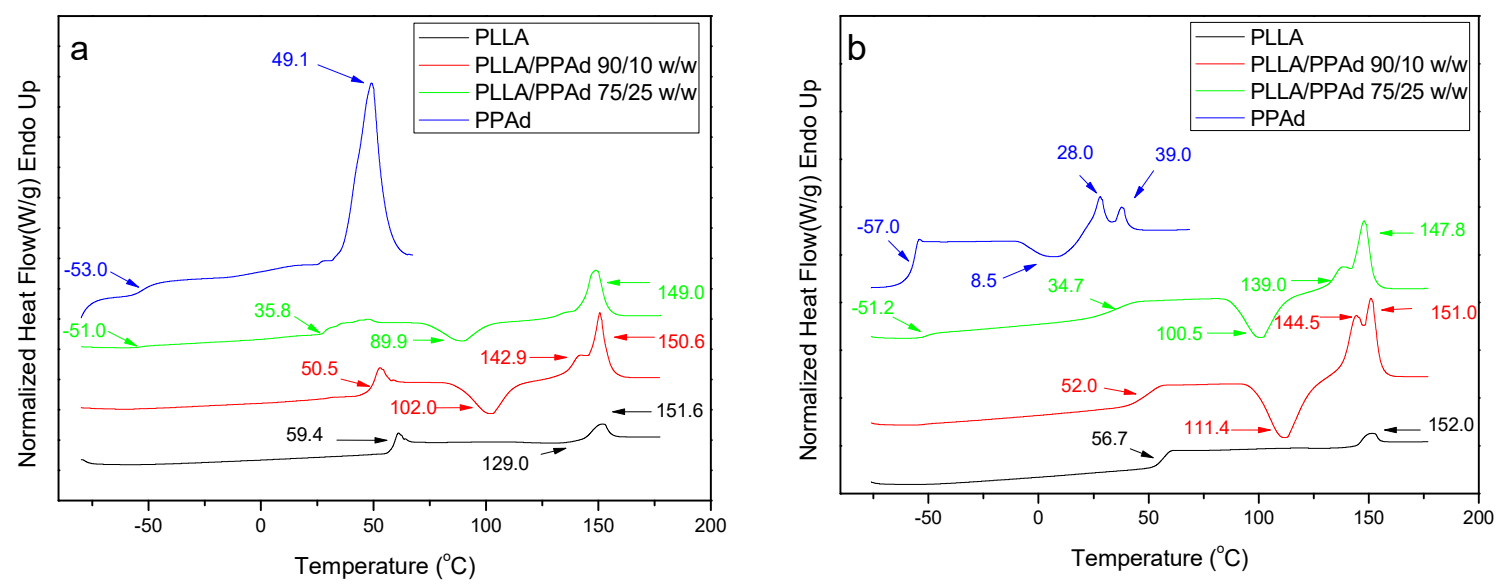

Figure 6. Differential (a) first heating and (b) second heating scanning calorimetric thermograms of neat polymers and synthesized copolymers.

Table 2. Glass transition temperature $\left(T_{\mathrm{g}}\right)$, cold crystallization temperature $\left(T_{\mathrm{cc}}\right)$ and melting temperature $\left(T_{\mathrm{m}}\right)$ of PLLA, PPAd and their copolymers.

\begin{tabular}{|c|c|c|c|c|c|c|c|c|c|c|}
\hline \multirow{2}{*}{ Sample } & \multicolumn{4}{|c|}{$T_{\mathrm{g}}\left({ }^{\circ} \mathrm{C}\right)$} & \multicolumn{2}{|c|}{$T_{\mathrm{c}}\left({ }^{\circ} \mathrm{C}\right)$} & \multicolumn{4}{|c|}{$T_{\mathrm{m}}\left({ }^{\circ} \mathrm{C}\right)$} \\
\hline & $T_{\mathrm{g} 1}$ & $T_{\mathrm{g} 2}$ & $T_{\mathrm{g} 1}{ }^{\prime}$ & $T_{\mathrm{g} 2^{\prime}}$ & $T_{\mathrm{cc}}$ & $T_{\mathrm{cc}}{ }^{\prime}$ & $T_{\mathrm{m} 1}$ & $T_{\mathrm{m} 2}$ & $T_{\mathrm{m} 1^{\prime}}$ & $T_{\mathrm{m} 2}{ }^{\prime}$ \\
\hline PLLA & 59.4 & - & 56.7 & - & 129.0 & - & 151.6 & - & 152.0 & - \\
\hline PLLA/PPAd 90/10 & 50.5 & - & 52.0 & - & 102.0 & 111.4 & 142.9 & 150.6 & 144.5 & 151.0 \\
\hline PLLA/PPAd 75/25 & 38.8 & -51.0 & 34.7 & -51.2 & 89.9 & 100.5 & 149.0 & - & 139.0 & 147.8 \\
\hline PPAd & -53.0 & - & -53.0 & - & - & 8.5 & 49.1 & - & 28.0 & 39.0 \\
\hline
\end{tabular}

Abbreviations: $T_{\mathrm{g}^{\prime}} T_{\mathrm{cc}}{ }^{\prime} T_{\mathrm{m}}{ }^{\prime}$ referring to second heating.

Completely amorphous samples were obtained after melt quenching and their thermograms are presented in Figure 6B. After the second heating process all synthesized copolymers exhibit a double peak at the melting point. The presence of the double peak is due either to the formation of two different crystals formed after the first melting or to the formation of a constituent copolymer where each peak corresponds to a different cluster [16]. The $T_{\mathrm{g}}$ and $T_{\mathrm{cc}}$ values are very close to the ones recorded during the first heating with some small differences. As PLLA and PPAd are semicrystalline, the presence of both peaks is expected in the DSC thermographs of the copolymers [25]. However, the $T_{\mathrm{m}}$ of PPAd was not recorded, due to its low crystallization rate. This is also confirmed by the XRD of PLLA-b-PPAd copolymers in which only some peaks of PLLA are recorded (Figure 5).

Thermal degradation of neat PLLA, PPAd and PLLA- $b$-PPAd 90/10 and 75/25 $w / w$ copolymers was studied by determining their mass loss during heating, with thermogravimetric analysis (TGA). The mass loss (TG\%) and the derivative mass loss (DTG) curves at a heating rate of $10^{\circ} \mathrm{C} / \mathrm{min}$ are presented in Figure 7. With regard to thermal degradation mechanisms, PPAd is degraded in 2 steps with a maximum decomposition temperature of $410^{\circ} \mathrm{C}$. Aliphatic polyesters generally undergo $\beta$ and $\alpha$ - hydrogen bond scissions, yielding low molecular weight volatile products, such as $\mathrm{CO}_{2}$, $\mathrm{H}_{2} \mathrm{O}$, aldehydes, ketones, and allylic products $\left(\mathrm{H}_{2} \mathrm{C}=\mathrm{CH}-\mathrm{CH}_{2} \mathrm{R}\right)$ [26]. In the case of PLLA, only one degradation step was observed, with a maximum decomposition temperature of $376^{\circ} \mathrm{C}$. The main reaction pathway is an intramolecular transesterification, affording cyclic oligomers [27]. In addition, acrylic acid from cis-elimination as well as carbon oxides and acetaldehyde from fragmentation reactions have also been observed. The onset of thermal degradation of neat PLLA, in spite of exhibiting a faster thermal degradation than the PLLA/PPAd copolymers, is observed at a higher temperature than for copolymers. PLLA/PPAd 90/10 and 75/25 $w / w$ copolymers follow a two-stage degradation. The lactide-rich sequences degrade first, and the PPAd-rich domains later. However, in neat PLLA the average sequence length of crystallizable lactide units is much larger, leading to a higher and more 
compact crystalline fraction than in copolymers, hence the onset of thermal degradation is delayed in neat PLLA because of the lower accessibility of lactide units when arranged in close compact crystallite aggregates [28]. Table 3 shows the temperatures at which polyesters exhibited $2 \%, 50 \%$ and $98 \%$ mass loss, as well as temperatures with the maximum rate of mass loss.


Figure 7. (A) Mass loss as a function of temperature with heating rate $\beta=10^{\circ} \mathrm{C} / \mathrm{min}$. (B) Differential mass loss as a function of temperature, with heating rate $\beta=10^{\circ} \mathrm{C} / \mathrm{min}$.

Table 3. Data obtained by thermogravimetric analysis of synthesized polymers.

\begin{tabular}{cccccc}
\hline Samples & $\boldsymbol{T}_{\mathbf{d}} \mathbf{2} \mathbf{\%}\left({ }^{\circ} \mathbf{C}\right)$ & $\boldsymbol{T}_{\mathbf{d}} \mathbf{} \mathbf{5 0} \%\left({ }^{\circ} \mathbf{C}\right)$ & $\boldsymbol{T}_{\mathbf{d}}, \mathbf{9 8} \%\left({ }^{\circ} \mathbf{C}\right)$ & $\boldsymbol{T}_{\max }\left({ }^{\circ} \mathbf{C}\right)$ & $\operatorname{Residue~}(\mathbf{\%}) \mathbf{5 0 0}{ }^{\circ} \mathbf{C}$ \\
\hline PLLA & 322.4 & 370.3 & 390.5 & 376.3 & 1.01 \\
PLLA/PPAd 90/10 & 226.5 & 357.0 & 394.5 & 362.7 & - \\
PLLA/PPAd 75/25 & 287.0 & 367.4 & 455.9 & 364.3 & 1.95 \\
PPAd & 308.9 & 404.5 & Residue & 410.0 & 2.97 \\
\hline
\end{tabular}

Polyester erosion via the hydrolysis of the ester bonds is one of the main mechanisms of drug release from such polymeric-based systems. Hence, the evaluation of hydrolysis is of crucial importance. As mentioned earlier, the in vivo hydrolysis of PLLA is slow and hence time-consuming [29]. It is thus a common practice to evaluate the hydrolytic degradation in the presence of enzymes [17]. More specifically, in the present work, the enzymatic hydrolysis of PLLA, PPAd and their copolymers was studied using a mixture of Rhizopus oryzae and Pseudomonas cepacia lipases. These lipases are activated by adsorption on hydrophobic surfaces and consequently are able to cleave ester bonds in the solid phase. As illustrated in Figure 8, neat PLLA showed only limited mass loss during hydrolysis in the presence of enzymes, with approximately $0.3 \%$ of the initial mass being lost within the first eight days. No further changes in PLLA mass loss were recorded for up to 18 days (data not shown). On the contrary, PPAd was fully hydrolyzed within three days in the presence of enzymes, indicating that the prepared polyester is fully biodegradable in a short time. The different behavior of polyesters during hydrolysis can be attributed to several factors such as differences in molecular weight, hydrophilic/hydrophobic balance, degree of crystallinity, crystal morphology and melting point [30]. With regard to PLLA/PPAd copolymers, the recorded mass loss rates during enzymatic hydrolysis were near the rates recorded for neat PLLA. Specifically, results in Figure 8 show that as the PPAd content increased in the copolymers, the enzymatic hydrolysis rate slightly increased with approximately $0.9 \%$, and $1.4 \%$ of mass loss being recorded within three days for copolymers having 10 and $25 \mathrm{wt} \%$ PPAd, respectively. Therefore, it can be safely assumed that the PPAd content of copolymers affected the enzymatic hydrolysis only to a limited extent. The molecular weight as well as the high $T_{\mathrm{m}}$, which are close to neat PLLA, had probably a more important impact. 


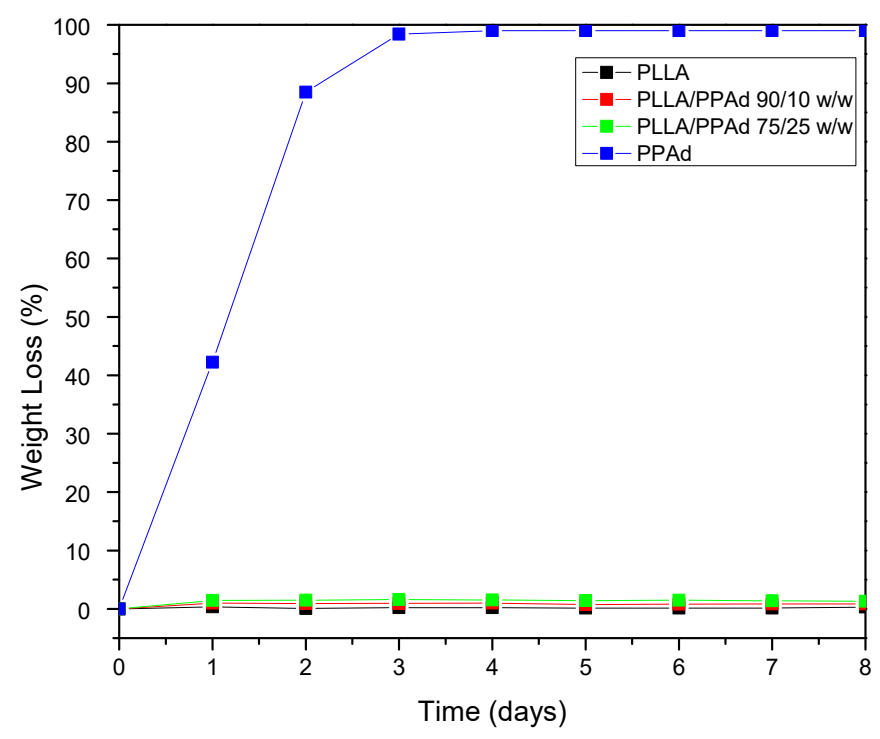

Figure 8. Weight loss versus time of neat PLLA, neat PPAd and PLA/PPAd copolymers at various weight ratios during hydrolysis test in the presence of enzymes at $37^{\circ} \mathrm{C}$ and $\mathrm{pH} 7$.

The morphology of enzymatically hydrolyzed polymers was further examined by SEM. Figure 9 shows the photos taken during the first three days of enzymatic hydrolysis. As shown, the PLLA sample did not change significantly, an expected observation in accordance with the weight loss data. In the case of neat PPAd signs of enzymatic hydrolysis were obvious from the first day: the surface appears to have holes that are progressively growing. Furthermore, the surface became rough with the presence of cracks probably owing to the amorphous fragments of PPAd [30]. With regard to PLLA/PPAd copolymers, structural deterioration on the surface texture of the films was not observed and an appearance close to neat PLLA is clear. The results of SEM micrographs are in full agreement with the mass loss measurements.

\subsection{Microparticles Characterization}

The prepared copolymers were used for the microencapsulation of NTX drug, applying the single emulsification method. Both the synthesized polyesters and NTX are soluble in DCM. Microparticles were obtained as evidenced by the SEM photos. As observed in Figure 10 all the microparticles had a spherical morphology with smooth surfaces and without agglomeration. Microparticles prepared using PLLA had sizes ranging between 2.6 and $4.5 \mu \mathrm{m}$. The sizes for the other microspheres ranged between 2-4 $\mu \mathrm{m}$ for PLLA- $b$-PPAd 90/10, 0.8-2 $\mu \mathrm{m}$ for PLLA- $b$-PPAd 75/25 and 0.4-0.8 $\mu \mathrm{m}$ for PPAd. The size of the microparticles was affected by the PPAd content in the copolymer; i.e., as the content of PPAd increased, the size of the microparticles decreased. Concerning homopolymers this could be attributed to the low molecular weight of PPAd (lower than half the molecular weight of PLLA). Regarding the copolymers, the reduced size could be attributed either to the molecular weight compared with that of PLLA, either to the length of the block segments. Indeed, the length of the PLA segment in copolymer 90/10 is expected to be higher than in copolymer 75/25 and as the length of PLLA segment decreased, smaller particles were formed. 


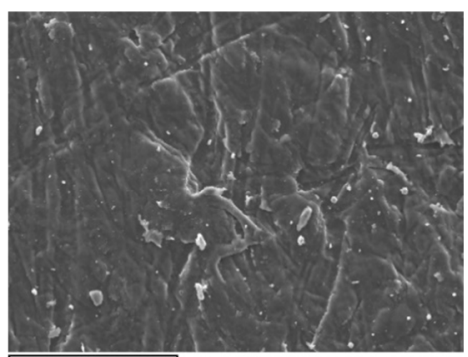

PLLA (1 d )

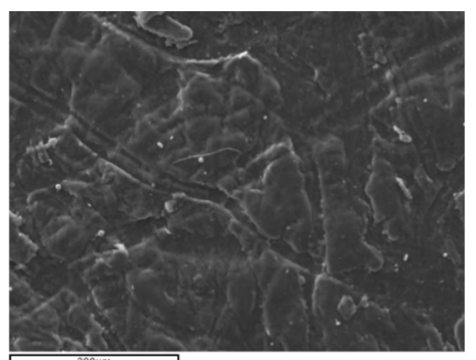

PLLA/PPAd 90/10 (1 d)

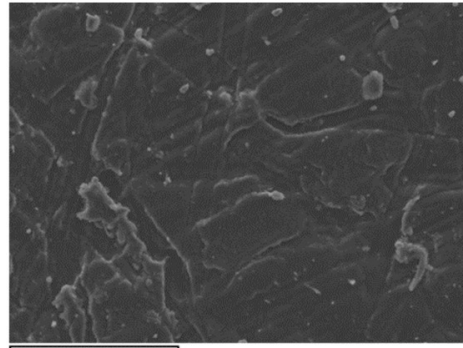

PLLA/PPAd 75/25 (1 d)

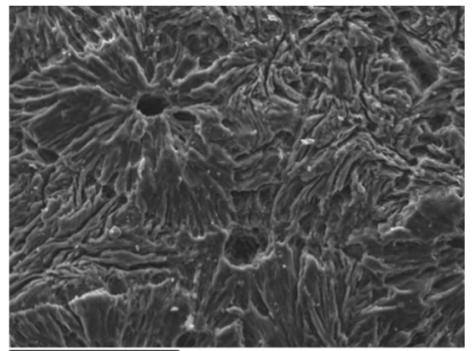

PPAd (l d)

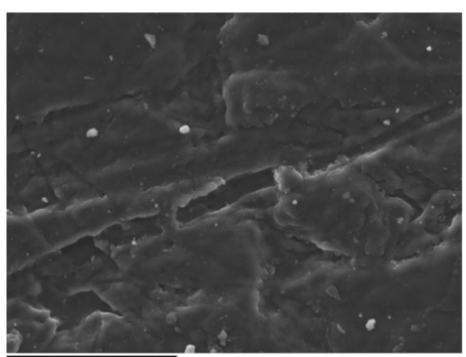

PLLA (2 d )

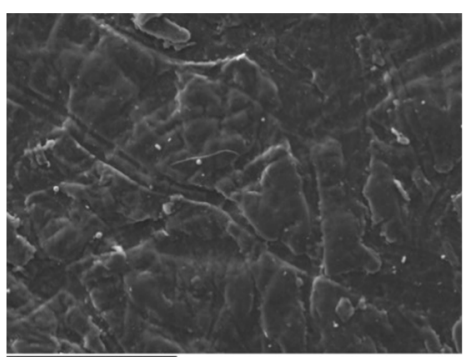

PLLA/PPAd 90/10 (2 d)

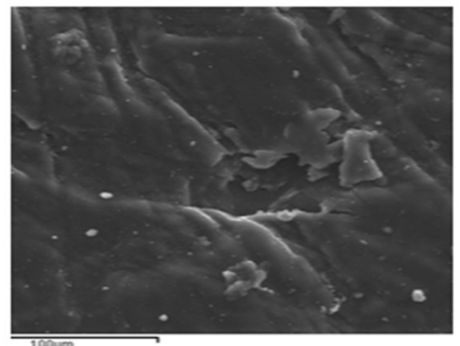

PLLA/PPAd 75/25 (2 d)

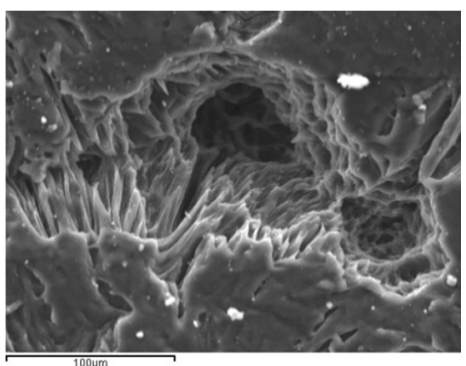

PPAd (2 d)

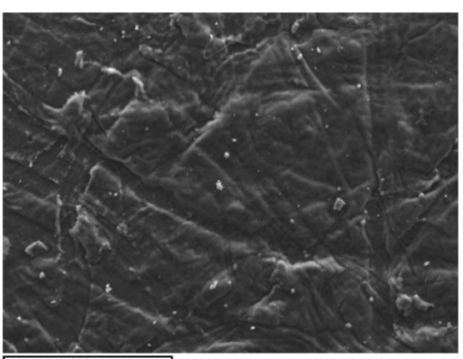

PLLA (3 d)

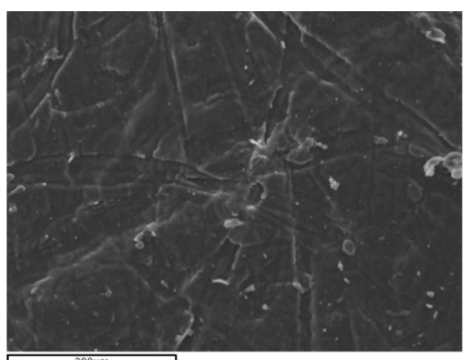

PLLA/PPAd 90/10 (3 d)

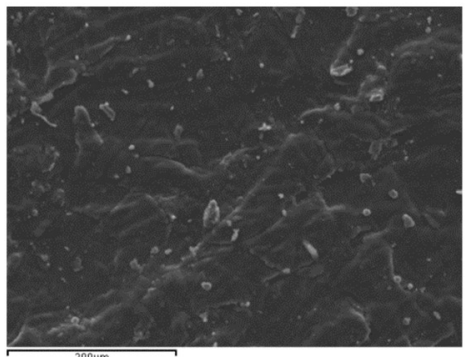

PLLA/PPAd 75/25 (3 d)

Figure 9. Scanning electron microscopy (SEM) micrographs for surfaces of enzymatic hydrolysis (1-3 days): neat PLLA, neat PPAd, PLLA- $b$-PPAd 90/10 and PLLA- $b$-PPAd 75/25 w/w.

Table 4 presents the yields of microparticles, drug loading, and entrapment efficiency (EE). The yield of microparticles varied from $54.8 \%$ (in the case of block copolymer $75 / 25$ ) to $62.5 \%$ (in the case of pure PLLA), indicating high process efficacy. Drug loading varied from $8.75 \%$ (in the case of PLLA) to $3.63 \%$ (in the case of pure PPAd) and \% EE varied from $35.00 \%$ in the case of pure PLLA to $14.53 \%$ in the case of pure PPAd. Several factors may affect both drug loading and \% EE, such as the affinity of the loaded drug with the polyesters, the hydrophobicity of the polymer matrix, the drug solubility in water, drug-drug interactions (i.e., its ability to self-aggregate), etc. It was observed that as the PPAd content increased, the drug loading and EE decreased. This may be attributed to the stereochemical inhibition of NTX and PPAd, as NTX has a relative rigid structure while PPAd is more flexible. 

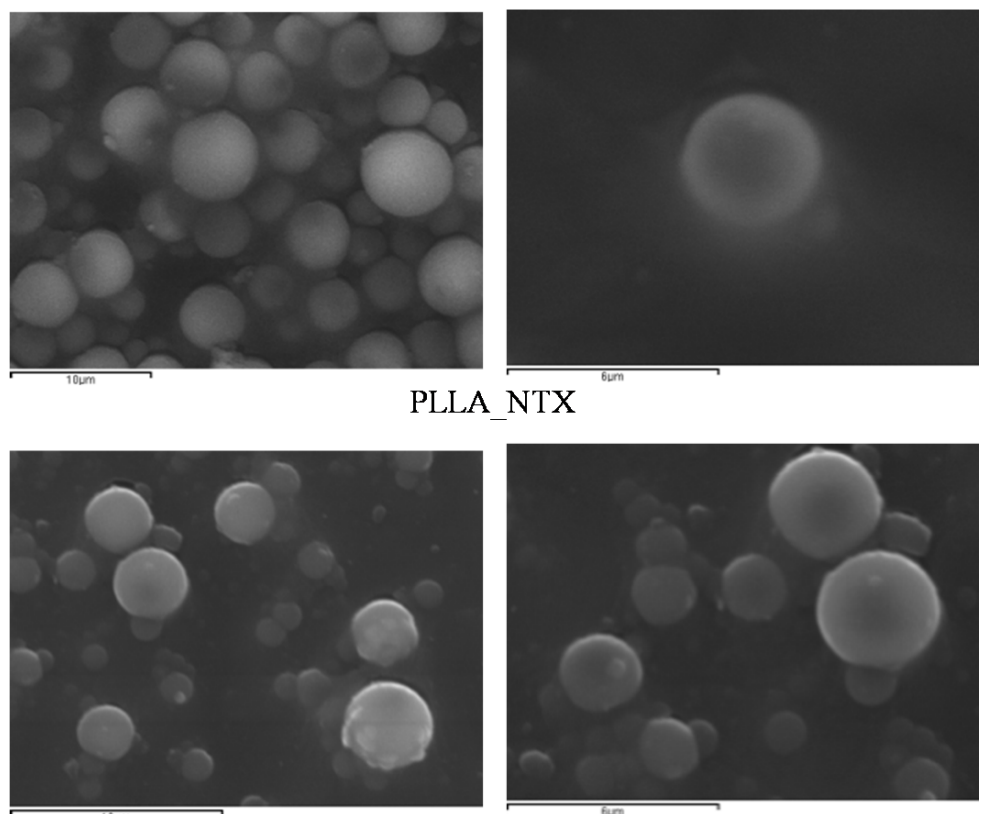

PLLA/PPAd 90/10_NTX
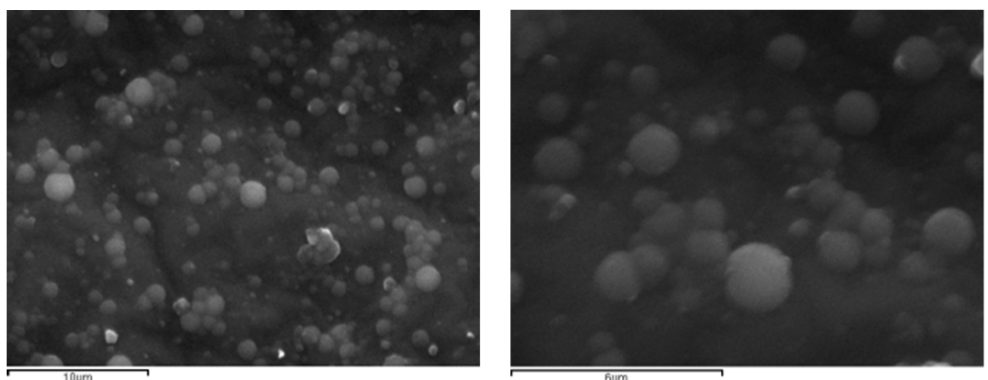

PLLA/PPAd 75/25_NTX
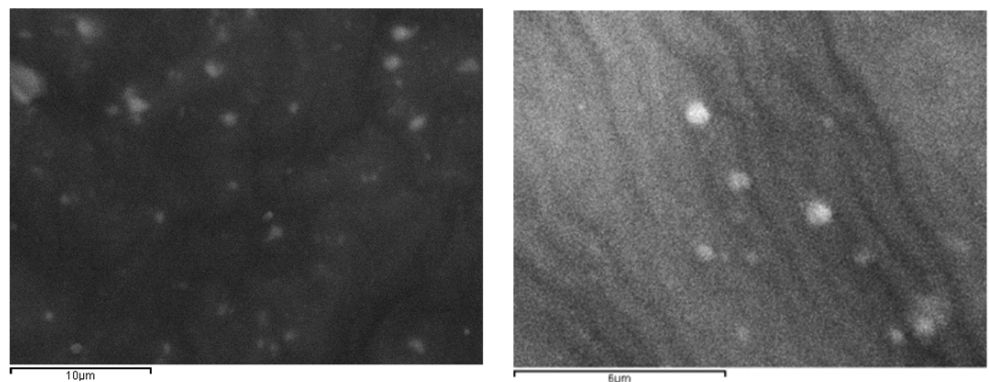

PPAd NTX

Figure 10. SEM micrographs of prepared microparticles loaded with naltrexone base (NTX).

Table 4. Characteristics of prepared naltrexone-loaded microparticles such as yield of microparticles $(\%)$, drug loading (\%), and entrapment efficiency (\%).

\begin{tabular}{ccccc}
\hline Sample & Diameter $(\boldsymbol{\mu m})$ & $\begin{array}{c}\text { Yield of } \\
\text { Microparticles (\%) }\end{array}$ & Drug Loading (\%) & $\begin{array}{c}\text { Entrapment } \\
\text { Efficiency (\%) }\end{array}$ \\
\hline PLLA & $2.6-4.5$ & $62.5 \pm 2.0$ & $8.75 \pm 0.22$ & $35.00 \pm 2.02$ \\
PLLA/PPAd 90/10 & $2.0-4.0$ & $61.7 \pm 3.6$ & $8.30 \pm 0.21$ & $33.21 \pm 1.62$ \\
PLLA/PPAd 75/25 & $0.2-2.0$ & $54.8 \pm 1.2$ & $5.89 \pm 0.22$ & $23.55 \pm 1.02$ \\
PPAd & $0.4-0.8$ & $58.9 \pm 4.5$ & $3.63 \pm 0.15$ & $14.53 \pm 0.82$ \\
\hline
\end{tabular}

API solid state properties and physical state have an important role in the chemical and physical stability of the prepared formulations. FTIR was used in order to examine a possible bond formation 
between the drug and the polyesters in the prepared microparticles. FTIR spectra of NTX-loaded microparticles (Figure 11) showed all the characteristic peaks of NTX and the copolymers. In the FTIR spectrum of NTX, the absorption band at $3000-3100 \mathrm{~cm}^{-1}$ is assigned to the $v(\mathrm{C}-\mathrm{H})$ vibrations of the benzene rings, peaks at 1508 and $1617 \mathrm{~cm}^{-1}$ to the vibration of $v(C=C)$ bonds. In the $v(C-C)$ and $v(\mathrm{C}-\mathrm{O})$ regions, NTX exhibits sharp absorption peaks at $1456 \mathrm{~cm}^{-1}$ and $1239 \mathrm{~cm}^{-1}$ respectively, a peak at $1727 \mathrm{~cm}^{-1}$ corresponding to its $v(\mathrm{C}=\mathrm{O})$ vibration modes, and a broad peak in the range $3200-3500 \mathrm{~cm}^{-1}$ due to the existence of OH groups [11]. After the incorporation of NTX, the FTIR spectra of microparticles showed shifts in the region of $\mathrm{OH}$ and $\mathrm{C}=\mathrm{O}$ groups. For example, in PLLA_NTX, a shift was observed from 3664 to $3672 \mathrm{~cm}^{-1}$, i.e., to higher wavenumbers, indicating that interactions took place with NTX. Additionally, shifts were also observed in the area of $\mathrm{C}=\mathrm{O}$, indicating hydrogen bond formation. Similar shifts were noticeable for all microparticles showing that strong interactions between the drug and the polymeric matrices took place in all cases.

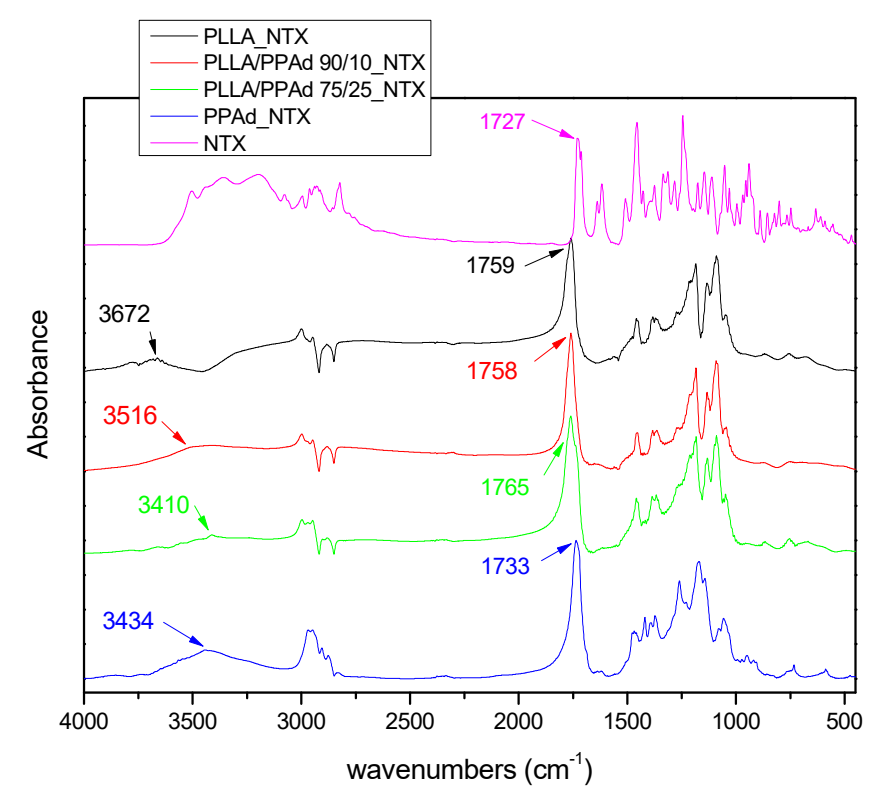

Figure 11. Fourier-transformed infrared (FTIR) spectra of neat naltrexone and prepared naltrexone microspheres with PLLA, PPAd, and PLA-b-PPAd copolymers at several weight ratios.

XRD was used in order to examine the crystallinity of NTX before and after its encapsulation. As it can be observed in Figure 12, NTX is a highly crystalline drug with two sharp peaks at $2 \theta=12.9^{\circ}$ and $16.6^{\circ}$, three weaker ones at $21.6^{\circ}, 22.5^{\circ}$ and $37.7^{\circ}$ and some much smaller ones [31]. After encapsulation in microparticles no crystallinity of the drug was observed. An exception was the microparticles prepared with PLLA where a small peak at $16.7^{\circ}$ was observed. This peak could be attributed either to NTX, meaning that the drug is in a crystalline state in microparticles, either to another type of crystalline formation of the polymer, due to the fact that PLLA has a sharp peak at $17.2^{\circ}$, and the presence of NTX could affect its structure. In microparticles prepared with PPAd it seems that a semicrystalline formulation was obtained mainly ought to the polymer rather than NTX. DSC was further used to confirm these observations. 


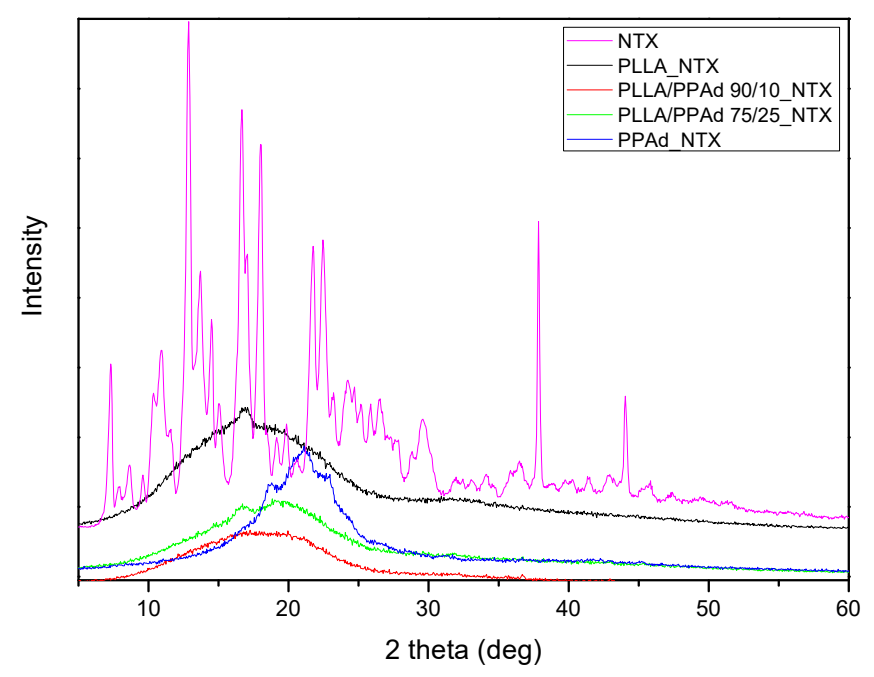

Figure 12. X-ray diffraction (XRD) patterns of neat naltrexone and prepared naltrexone microspheres with PLLA, PPAd, and PLLA- $b$-PPAd 90/10 and 75/25 $w / w$ copolymers.

As shown in Figure 13, a sharp endothermic peak is present for NTX at $177.1^{\circ} \mathrm{C}$ [11]. Concerning the DSC curves of the prepared microparticles, the peak of $T_{\mathrm{m}}$ of NTX was not observed in any formulation indicating that the drug is present in an amorphous state in the microparticles, as was already suggested by XRD. Thermal properties of the polymers after NTX encapsulation, were also studied and some differences compared with neat polymers were observed. In PLLA microparticles, the $T_{\mathrm{cc}}$ and $T_{\mathrm{m}}$ values of PLLA changed from 129.0 and 151.6 to 124.6 and $147.9^{\circ} \mathrm{C}$, respectively, after NTX encapsulation. Similar changes in the $T_{\mathrm{g}}$ and $T_{\mathrm{m}}$ values of PPAd in microparticles were also observed. $T_{\mathrm{g}}$ and $T_{\mathrm{m}}$ of PPAd shifted from -53.0 and $49.1^{\circ} \mathrm{C}$ to -51.7 and $39.7^{\circ} \mathrm{C}$, respectively, showing that the NTX also affected PPAd's structure. For microparticles prepared by copolymers, changes in their characteristic temperatures were also observed; $T_{\mathrm{g}}$ related to PLLA segment shifted from 50.5 to $52.5^{\circ} \mathrm{C}$, after NTX incorporation in PLA-b-PPAd 90/10 $w / w$, and its value appeared at $47.0^{\circ} \mathrm{C}$ in PLA-b-PPAd 75/25 $w / w$. Concerning the $\mathrm{T}_{\mathrm{m}}$ value due to the PPAd segment it shifted from 35.8 to $36.1{ }^{\circ} \mathrm{C}$ in PLA-b-PPAd $75 / 25 w / w$ and appeared at $30.6{ }^{\circ} \mathrm{C}$ in PLA-b-PPAd $90 / 10 w / w$. From all these it is clear that drug loading affects slightly the thermal properties of the polymers.

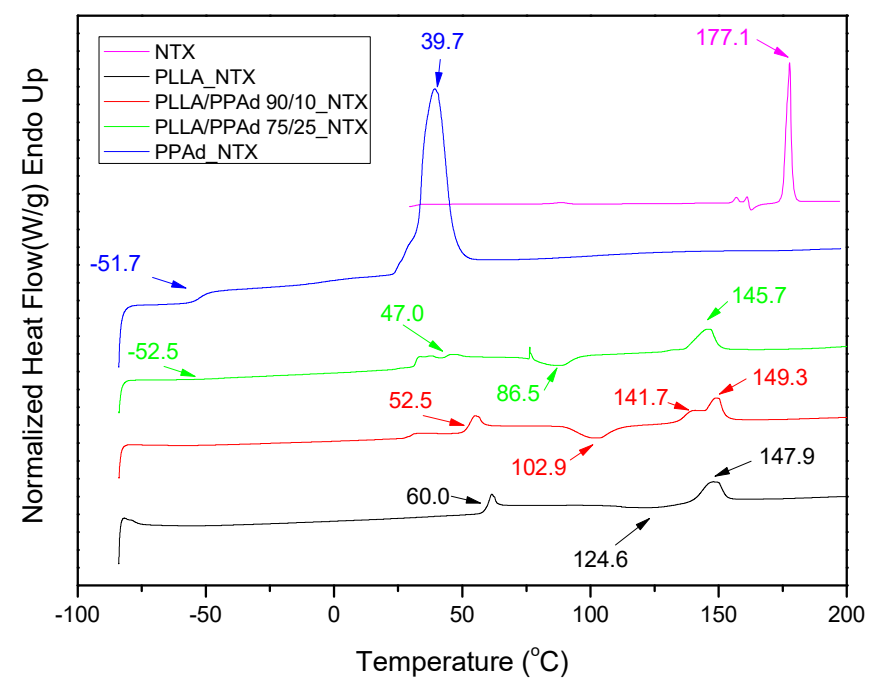

Figure 13. DSC thermograms of neat naltrexone and PLLA, PPAd, and PLA-b-PPAd 90/10 and 75/25 $w / w$ microspheres loaded with naltrexone. 
Naltrexone's release profile from the microparticles was studied in phosphate buffered saline, at $\mathrm{pH} 7.4$, containing Tween 20 (final concentration $0.2 \% v / v$ ). The dissolution profiles are shown in Figure 14. As it can be observed, there is an initial burst effect in all formulations in the first two hours reaching at about $30 \%$. Thereafter each polymer showed a different behavior. Concerning PLLA, $36 \%$ of NTX was released from the microparticles, the release lasted half a day with no further changes after that time. PPAd exhibited a three-stage release. A burst release, as referred previously, with $30 \%$ release within the first two hours, followed by a second stage, with a reduced release rate. A total release of $93 \%$ was observed within two days. Finally, in the last stage, which lasted until the fourth day, a release of $98.5 \%$ was reached. The copolymers showed intermediate release rates, between neat polymers, with PLLA- $b$-PPAd $90 / 10$ and 75/25 release lasting six and five days in which $82 \%$ and $90 \%$ of the drug was released, respectively. According to these release profiles it is clear that the prepared copolymers have a better profile, compared with PLLA, and could be promising matrices for long-acting release formulations of naltrexone for at least one week.

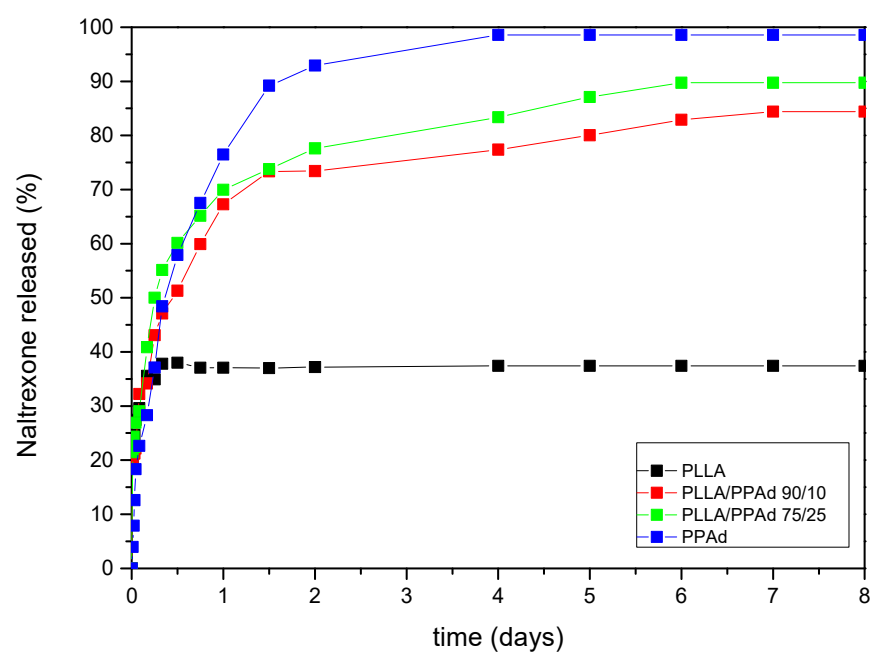

Figure 14. In vitro release profiles of neat naltrexone, along with NTX-loaded microspheres prepared from PLLA, PPAd and PLLA/PPAd copolymers.

Release profile is affected by many parameters such as the crystallinity of the drug, the microparticles size, diffusion and thermal properties of polymers. The drug was amorphous in all microparticles, a feature that enhanced its dissolution. The initial burst effect could be attributed to NTX located at the surface of the microparticles, since NTX is hydrophobic and could not be removed during washing steps. After that, diffusion of the drug took place leading to slower release rates [16,17]. Concerning PLLA, Cha and Pitt prepared microparticles of PLLA, PLGA and PCL of Naltrexone base by single emulsification method [32]. It was found that release of NTX from PLLA microparticles was negligible, probably due to steric accessibility of the drug. This result is in agreement with the observation in our study where after the first two hours, no significant release was observed from PLLA microparticles. The same team also used PCL in microparticles preparation and found that NTX was completely released in two days. This was attributed to Fickian diffusion, due to the low $T_{\mathrm{g}}$ of the polymer [32]. In analogy to PCL, in the present work, NTX release from PPAd microparticles reached $98 \%$ in 4 days. This could be due to the low $T_{\mathrm{m}}$ and $T_{\mathrm{g}}$ of the microparticles ( $T_{\mathrm{g}}$ was found to be $-51.7^{\circ} \mathrm{C}$, a value much lower than $37^{\circ} \mathrm{C}$ where the dissolution study was conducted).

The diffusion of NTX through the amorphous polymeric matrix appears to be easier due to the higher mobility of the polyester macromolecules in the amorphous state, allowing an easier penetration of the dissolution medium and, as a result, a faster drug release. Moreover, the thermal properties of the polymer can also affect drug release. When the polymer is exposed to temperatures above the glass transition temperature $\left(T_{\mathrm{g}}\right)$, an increase in free volume is observed, which allows for a greater 
segmental chain mobility and a faster drug delivery. According to the DSC, the $T_{\mathrm{g}}$ of PPAd is $-51.7^{\circ} \mathrm{C}$ while PLLA- $b$-PPAd 75/25 $w / w$ has also a similar $T_{\mathrm{g}}$, as well as one corresponding to the $T_{\mathrm{g}}$ of PLLA (Table 2). The copolymer has a lower degree of crystallinity, compared to neat PPAd (Table 1), and thus a higher release rate was expected. However, this is not the case. As it can be seen in Figure 14, PPAd has a higher release rate than PLLA- $b$-PPAd copolymer. This behavior should be attributed to the existence of the PLLA segment in the copolymers, which has a lower mobility than PPAd. This was further confirmed with PLLA-b-PPAd 90/10 $w / w$ copolymer, which, due to the higher PLLA amount, exhibits slower release than the 75/25 $w / w$ copolymer. The exposure of microparticles with neat PPAd and copolymers with higher PPAd amount at $37^{\circ} \mathrm{C}$, could explain the fast rate of drug release [32,33], indicating that NTX was probably released from microspheres by diffusion. So, it is clear that PLLA, due to its high $T_{\mathrm{g}}$, delays the release of NTX and its copolymerization with PPAd could enhance the release rate of NTX.

Figure 15 presents the morphology of the prepared microparticles after 8 days of dissolution, via SEM micrographs. It is clear that the surface of all the microspheres changed since the drug was dissolved. In all cases, aggregation of the microspheres was observed, their surface became rougher, and the normal spherical shape observed in the original microspheres was modified. PPAd microparticles exhibited extensive aggregation and their shape was destroyed. The presence of cavities in the internal morphology of the microspheres has not been confirmed, indicating that there is no erosion of the polymeric matrix. Thus, it is clear that diffusion was the main mechanism of drug release of these microparticles.

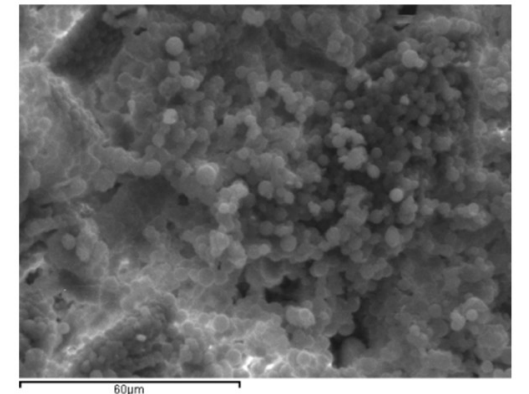

PLLA_NTX

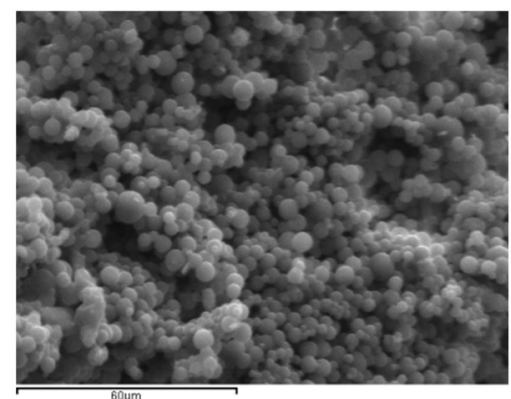

PLLA/PPAd 75/25_NTX

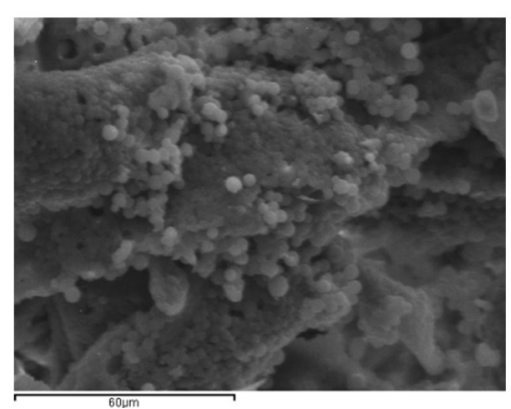

PLLA/PPAd 90/10_NTX

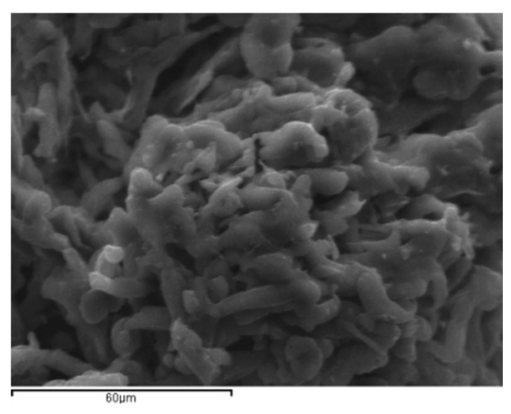

PPAd_NTX

Figure 15. SEM images of NTX-loaded microspheres after 8 days of dissolution.

\subsection{Release Data Modeling}

According to the previous discussion and based on the experimental evidence, it appears that there is no polymer particle erosion, so the release is dominated by diffusion. This means that the drug release model must be a diffusion-based one. To set up the model the following assumptions are made: (i) the polymer particles are spherical, and they can be assumed to be monodispersed; (ii) the amount of the drug in the bath at the end of the release is much smaller than that corresponding to equilibrium. This is supported by the almost complete release for the case of PPAd. It appears 
that the non-released drug is trapped in the polymer matrix (maybe in an insoluble crystalline form); (iii) there is no mass transfer resistance to the bulk phase due to the agitation during release. There are approximate expressions for the diffusional release (in the form of power law in time functions) but they refer only to initial release stage [34]. Here the interest is to reproduce the whole release curve so the partial differential equation of transient diffusion must be solved.

There are several levels of complication of the diffusion problem. The first level refers to the mode of diffusion (Fickian/non-Fickian). The second level refers to the possibility of non-uniformity in the polymer structure leading to different release paths with different diffusion coefficients. The third level is the possibility of non-uniform drug concentration along the radius of the polymer particle. Having experimental evidence for the third level and no evidence for the other two, Fickian diffusion with a single diffusion coefficient and non-uniform drug concentration is considered as the starting point to model the data.

The governing equation is:

$$
\frac{\partial c}{\partial t}=D \frac{\partial^{2} c}{\partial r^{\prime 2}}+\frac{2 D}{r^{\prime}} \frac{\partial c}{\partial r^{\prime}}
$$

where $r^{\prime}$ is the radial coordinate in the particle, $c$ is the local drug concentration in the particle and $D$ is the diffusion coefficient in the particle for the mobile fraction of the drug. The particle radius is denoted by $R$ and the boundary conditions for Equation (7) are: $c=0$ at $r^{\prime}=R, \mathrm{~d} c / \mathrm{d} r^{\prime}=0$ at $r^{\prime}=0$ and $c\left(r^{\prime}\right)=c_{\mathrm{o}}\left(r^{\prime}\right)$ at $t=0$. In order to facilitate the mathematical treatment of the problem the following normalization is made: $c=C_{\text {ave }} f(r)$ where $C_{\text {ave }}$ is the average concentration of mobile drug in the particles, $\tau=D t / R^{2}$ and $r=r^{\prime} / R$. The governing equation takes the form:

$$
\frac{\partial f}{\partial \tau}=\frac{\partial^{2} f}{\partial r^{2}}+\frac{2}{r} \frac{\partial f}{\partial r}
$$

where the boundary conditions are $f=0$ at $r=1, \mathrm{~d} f / \mathrm{d} r=0$ at $r=0$ and $f(\mathrm{r})=f_{0}(r)$ at $\tau=0$. The function $f_{0}(r)$ denotes the initial drug distribution and by definition fulfills the relation $3 \int_{0}^{1} f_{0}(r) r^{2} d r=1$. According to the above model the release curve is computed as:

$$
\operatorname{drug} \operatorname{released}(\%)=M_{\infty}\left(1-3 \int_{0}^{1} f(r, t) r^{2} d r\right)
$$

where $M_{\infty}$ is the final \% drug released. The mathematical problem is now completely defined. A semi-analytical solution is possible by transforming the spherical to planar geometry (by introducing the new function $g(r)=r f(r))$ and exploiting the solutions of the planar problem [35]. The final result is:

$$
M=M_{\infty}\left(1-\frac{2}{\pi} \sum_{i=1}^{\infty} \frac{1}{i} e^{-i^{2} \pi^{2} \tau} \int_{0}^{1} r f_{0}(r) \sin (i \pi r) d r\right)
$$

It appears that for any profile of the initial drug distribution the functional form of the release curve is:

$$
M=M_{\infty}\left(1-\sum_{i=1}^{\infty} g_{i} e^{-i^{2} \pi^{2} \tau}\right)
$$

In the particular case of uniform initial profile, the coefficients $g_{i}$ take the form $g_{i}=6 /(i \pi)^{2}$.

At first the possibility of fitting the experimental release curves assuming a uniform drug distribution will be examined. The fitting variable is the diffusion coefficient $D$. The particle radius $R$ for each material is taken from the average diameter data presented in Table 4 . The fitting results appear in Figure 16. As it is clear the fitting quality is acceptable only for the case of PLLA. In the other cases there is a systematic deviation between the data and the fitted curves. The next step is to consider non-uniform drug profile. No specific shape of the profile needs to be assumed. The fitting to the data is performed employing relation (11) with fitting parameters the diffusion 
coefficient $D$ and the coefficients $g_{1}, g_{2}, g_{3}$ (assuming $g_{i}=0$ for $i>3$ ). The fitting curves are shown in Figure 16 and a major improvement of the fitting quality (compared to that for uniform profile) is observed. The improvement appears to increase from PLLA to PPAd implying increasing drug profile non-uniformity in the particular order. It is denoted that in all cases the fittings are made using the least square criterion.
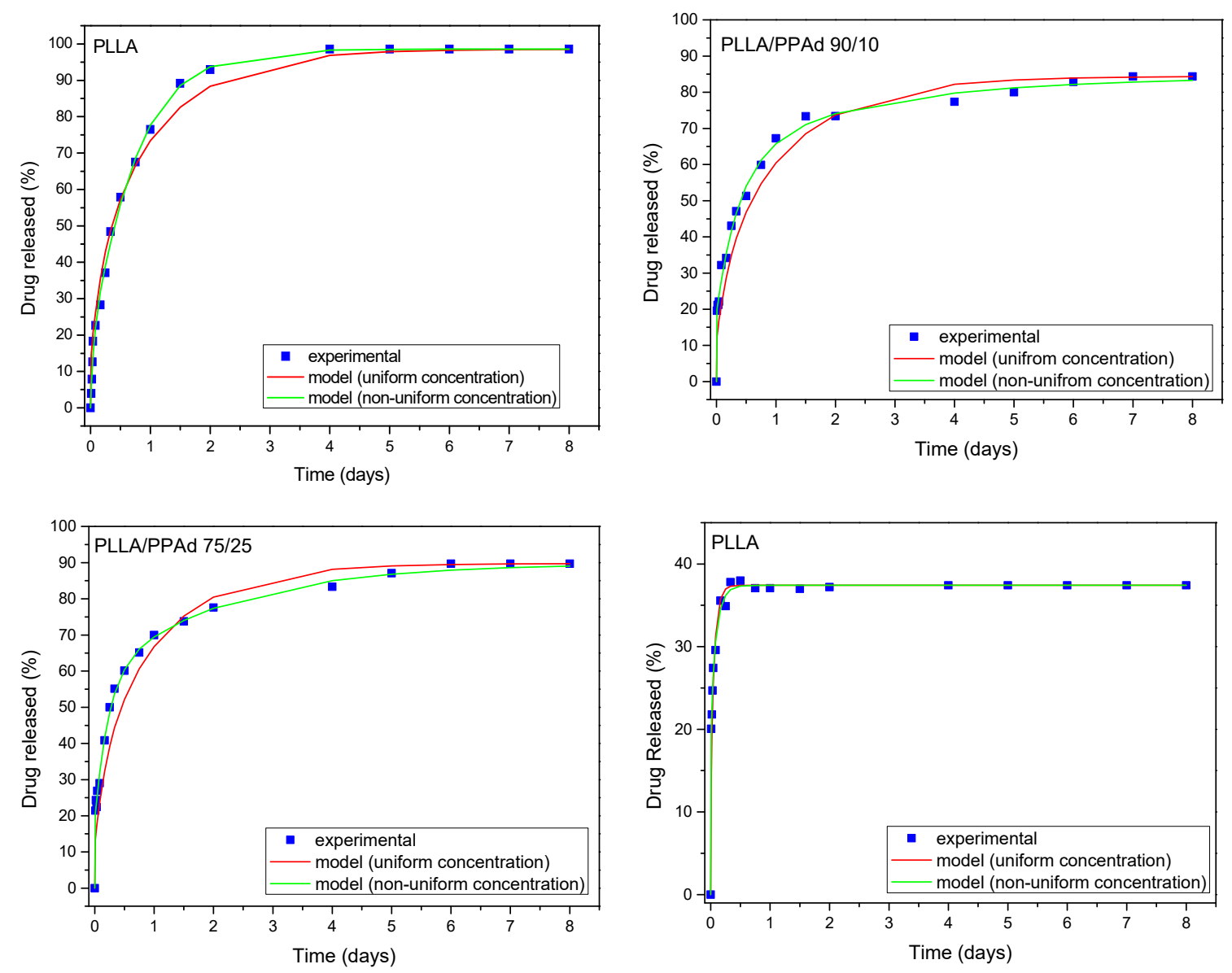

Figure 16. Experimental and model (for uniform and non-uniform drug profile) release curves.

The success of the model to describe the data suggests that drug profile non-uniformity is enough to describe the experimental data and the other levels of complication do not have to be invoked. It is worth noticing that the profile of drug that fits the data is not determined directly by this approach. An additional complicated inverse problem must be set to go from the fitting parameters to the actual profile [36]. The values of the diffusion coefficients that fit the data are: $8.67 \times 10^{-19} \mathrm{~m}^{2} / \mathrm{s}$ for PPAd, $8.75 \times 10^{-20} \mathrm{~m}^{2} / \mathrm{s}$ for PLLA/PPAd $75 / 25,1.45 \times 10^{-20} \mathrm{~m}^{2} / \mathrm{s}$ for PLLA/PPAd $90 / 10,1.55 \times 10^{-19} \mathrm{~m}^{2} / \mathrm{s}$ for PLLA. The diffusion coefficients are extremely small; almost ten order of magnitude smaller than those in liquids. It also appears that the diffusivity in neat polymers is higher than in polymer mixtures. The proposed model describes adequately the release data and it is compatible with the experimental observations of particle size and drug distribution non-uniformity.

\section{Conclusions}

PPAd and its copolymers with PLLA were successfully synthesized. According to GPC all polymers exhibited a unimodal distribution and the average molecular weights increased by increasing the percentage of PLLA in the copolymers. XRD measurements showed that PLLA had a higher crystallinity than PPAd, while all copolymers, due to the addition of PPAd segments, exhibited a lower degree of crystallinity than both homopolymers. This also affected their thermal properties. Indeed, 
DSC study revealed that an increase in PPAd content is associated with a concomitant decrease in the melting point and heat of fusion of copolymers. The enzymatic biodegradation study of polymers showed that PPAd had a very high degradation rate, compared to PLLA. This is probably due to the lower degree of crystallinity of PPAd over PLLA and to its lower melting point. However, due to the low percentage of PPAd in the prepared copolymers with PLLA, their enzymatic hydrolysis is almost similar to that of neat PLLA.

The microparticles prepared from the synthesized polymers for microencapsulation of the Naltrexone drug compound were spherical as illustrated by SEM micrographs, with average diameter ranging between $0.4-4.5 \mu \mathrm{m}$, depending on the polymer. From XRD, FTIR and DSC analysis, we concluded that amorphization of naltrexone occurred during microencapsulation, due to the strong interactions taking place between naltrexone and the polymeric matrices. The study of drug release showed that release is probably due to diffusion of NTX from microparticles, since no erosion was detected in nanoparticles by SEM. From dissolution studies it is clear that drug release is directly dependent on the polymer matrix used. Neat PPAd due to its low melting point and $T_{\mathrm{g}}$ values gave microparticles with the highest release while PLLA the lowest release. Copolymers showed an intermediate release depending on the copolymer composition. Naltrexone release is extended over seven days, indicating that these novel PLLA- $b$-PPAd copolymers could be used in long-acting injectable formulations of naltrexone drug. The fitting of a diffusion-based release model to the experimental release data suggests non-uniform drug loading of the particles.

Author Contributions: Methodology, original draft preparation, S.N.; investigation, formal analysis A.V.; methodology, investigation, writing, A.Z.; computation, release modeling, M.K.; supervision, writing-review and editing, G.Z.P.; supervision, writing-review and editing, D.N.B. All authors have read and agreed to the published version of the manuscript.

Funding: This research received no external funding.

Conflicts of Interest: The authors report no conflicts of interest. The authors alone are responsible for the content and writing of this article.

\section{References}

1. Rizzarelli, P.; Impallomeni, G.; Montaudo, G. Evidence of selective hydrolysis of aliphatic copolyesters induced by lipase catalysis. Biomacromolecules 2004, 5, 433-444. [CrossRef] [PubMed]

2. Paciello, A.; Amalfitano, G.; Garziano, A.; Urciuolo, F.; Netti, P.A. Hemoglobin-Conjugated Gelatin Microsphere as a Smart Oxygen Releasing Biomaterial. Adv. Healthc. Mater. 2016, 5, 2655-2666. [CrossRef] [PubMed]

3. Li, S.M.; Rashkov, I.; Espartero, J.L.; Manolova, N.; Vert, M. Synthesis, characterization, and hydrolytic degradation of PLA/PEO/PLA triblock copolymers with long poly(L-lactic acid) blocks. Macromolecules 1996, 29, 50-56. [CrossRef]

4. Mai, S.M.; Abbot, A.; Norton, D.; McKean, R.; Ryan, A.J. Synthesis and characterization of block copolymers of polyoxyethylene and polylactide with different architectures. Macromol. Chem. Phys. 2009, 210, 840-851. [CrossRef]

5. Hulse, G.K. Improving clinical outcomes for naltrexone as a management of problem alcohol use. Br. J. Clin. Pharmacol. 2013, 76, 632-641. [CrossRef] [PubMed]

6. Goonoo, N.; Bhaw-Luximon, A.; Ujoodha, R.; Jhugroo, A.; Hulse, G.K.; Jhurry, D. Naltrexone: A review of existing sustained drug delivery systems and emerging nano-based systems. J. Control. Release 2014, 183, 154-166. [CrossRef]

7. Hulse, G.K.; Stalenberg, V.; McCallum, D.; Smit, W.; O’Neil, G.; Morris, N.; Tait, R.J. Histological changes over time around the site of sustained release naltrexone-poly(DL-lactide) implants in humans. J. Control. Release 2005, 108, 43-55. [CrossRef]

8. Akala, E.O.; Wiriyacoonkasem, P.; Pan, G. Studies on in vitro availability, degradation, and thermal properties of naltrexone-loaded biodegradable microspheres. Drug Dev. Ind. Pharm. 2011, 37, 673-684. [CrossRef] 
9. Salehi, R.; Nowruzi, K.; Salehi, S.; Khandaghi, A.A.; Davaran, S.; Entezami, A.A. Smart poly (N-isopropyl acrylamide)-block-poly (L-Lactide) nanoparticles for prolonged release of naltrexone. Int. J. Polym. Mater. Polym. Biomater. 2013, 62, 686-694. [CrossRef]

10. Pagar, K.P.; Vavia, P.R. Naltrexone-loaded poly[La-(Glc-Leu)] polymeric microspheres for the treatment of alcohol dependence: In vitro characterization and in vivo biocompatibility assessment. Pharm. Dev. Technol. 2014, 19, 385-394. [CrossRef]

11. Nerantzaki, M.; Skoufa, E.; Adam, K.V.; Nanaki, S.; Avgeropoulos, A.; Kostoglou, M.; Bikiaris, D. Amphiphilic block copolymer microspheres derived from castor oil, poly( $\varepsilon$-carpolactone), and poly(ethylene glycol): Preparation, characterization and application in naltrexone drug delivery. Materials 2018, 11, 1996. [CrossRef] [PubMed]

12. Mohajeri, S.A.; Yaghoubi, S.; Abdollahi, E.; Mirzazadeh Tekie, F.S.; Kamali, H.; Khodaverdi, E.; Hadizadeh, F. In-vivo study of naltrexone hydrochloride release from an in-situ forming PLGA-PEG-PLGA system in the rabbit. J. Drug Deliv. Sci. Technol. 2016, 36, 156-160. [CrossRef]

13. Karavelidis, V.; Bikiaris, D.; Avgoustakis, K. New thermosensitive nanoparticles prepared by biocompatible pegylated aliphatic polyester block copolymers for local cancer treatment. J. Pharm. Pharmacol. 2015, 67, 215-230. [CrossRef] [PubMed]

14. Karavelidis, V.; Giliopoulos, D.; Karavas, E.; Bikiaris, D. Nanoencapsulation of a water soluble drug in biocompatible polyesters. Effect of polyesters melting point and glass transition temperature on drug release behavior. Eur. J. Pharm. Sci. 2010, 41, 636-643. [CrossRef] [PubMed]

15. Solomon, O.F.; Ciuta, I.Z. Determination de la viscosite intrinseque de solutions de polymeres par une simple determination de la viscosite. J. Appl. Polym. Sci. 1962, 6, 683-686. [CrossRef]

16. Nanaki, S.G.; Pantopoulos, K.; Bikiaris, D.N. Synthesis of biocompatible poly(e-caprolactone)-blockpoly(propylene adipate) copolymers appropriate for drug nanoencapsulation in the form of core-shell nanoparticles. Int. J. Nanomed. 2011, 6, 2981-2995.

17. Nanaki, S.; Barmpalexis, P.; Iatrou, A.; Christodoulou, E.; Kostoglou, M.; Bikiaris, D.N. Risperidone controlled release microspheres based on poly(lactic acid)-poly(propylene adipate) novel polymer blends appropriate for long acting injectable formulations. Pharmaceutics 2018, 10, 130. [CrossRef]

18. Desroches, M.; Caillol, S.; Lapinte, V.; Auvergne, R.; Boutevin, B. Synthesis of biobased polyols by thiol-ene coupling from vegetable oils. Macromolecules 2011, 44, 2489-2500. [CrossRef]

19. Espartero, J.L.; Rashkov, I.; Li, S.M.; Manolova, N.; Vert, M. NMR analysis of low molecular weight poly(lactic acid)s. Macromolecules 1996, 29, 3535-3539. [CrossRef]

20. Nguyen, T.H.; Petchsuk, A.; Tangboriboonrat, P.; Opaprakasit, M.; Sharp, A.; Opaprakasit, P. Synthesis and characterizations of PLLA/PEG block copolymers. Adv. Mater. Res. 2010, 93-94, 198-201. [CrossRef]

21. Su, L.; Zou, J.; Dong, S.; Hao, N.; Xu, H. Influence of different $\beta$-nucleation agents on poly(L-lactic acid): Structure, morphology, and dynamic mechanical behavior. RSC Adv. 2017, 7, 55364-55370. [CrossRef]

22. Kister, G.; Cassanas, G.; Vert, M.; Pauvert, B.; Terol, A. Vibrational Analysis of Poly(L-lactic acid). J. Raman Spectrosc. 1995, 26, 307-311. [CrossRef]

23. Lu, X.; Hay, J. Isothermal crystallization kinetics and melting behaviour of poly(ethylene terephthalate). Polymer 2001, 42, 9423-9431. [CrossRef]

24. Daimon, H.; Okitsu, H.; Kumanotani, J. Glass transition behaviors of random and block copolymers and polymer blends of styrene and cyclododecyl acrylate. I. Glass transition temperatures. Polym. J. 1975, 7, 460-466. [CrossRef]

25. Huang, C.F.; Kuo, S.W.; Chen, J.K.; Chang, F.C. Synthesis and characterization of polystyrene-b-poly(4-vinyl pyridine) block copolymers by atom transfer radical polymerization. J. Polym. Res. 2005, 12, 449-456. [CrossRef]

26. Bikiaris, D.N.; Chrissafis, K.; Paraskevopoulos, K.M.; Triantafyllidis, K.S.; Antonakou, E.V. Investigation of thermal degradation mechanism of an aliphatic polyester using pyrolysis-gas chromatography-mass spectrometry and a kinetic study of the effect of the amount of polymerisation catalyst. Polym. Degrad. Stab. 2007, 92, 525-536. [CrossRef]

27. Kopinke, F.D.; Remmler, M.; Mackenzie, K.; Möder, M.; Wachsen, O. Thermal decomposition of biodegradable polyesters-II. Poly(lactic acid). Polym. Degrad. Stab. 1996, 53, 329-342. [CrossRef]

28. Fernández, J.; Etxeberria, A.; Sarasua, J.R. Synthesis, structure and properties of poly(L-lactide-co- $\varepsilon-$ caprolactone) statistical copolymers. J. Mech. Behav. Biomed. Mater. 2012, 9, 100-112. [CrossRef] 
29. Beslikas, T.; Gigis, I.; Goulios, V.; Christoforides, J.; Papageorgiou, G.Z.; Bikiaris, D.N. Crystallization study and comparative in vitro-in vivo hydrolysis of PLA reinforcement ligament. Int. J. Mol. Sci. 2011, 12, 6597-6618. [CrossRef]

30. Bikiaris, D.N.; Nianias, N.P.; Karagiannidou, E.G.; Docoslis, A. Effect of different nanoparticles on the properties and enzymatic hydrolysis mechanism of aliphatic polyesters. Proc. Polym. Degrad. Stab. 2012, 97, 2077-2089. [CrossRef]

31. Nidhi, K.; Indrajeet, S.; Khushboo, M.; Gauri, K.; Sen, D.J. Hydrotropy: A promising tool for solubility enhancement: A review. Int. J. Drug Dev. Res. 2011, 3, 26-33.

32. Cha, Y.; Pitt, C.G. The acceleration of degradation-controlled drug delivery from polyester microspheres. J. Control. Release 1989, 8, 259-265. [CrossRef]

33. Jelonek, K.; Kasperczyk, J. Polyesters and polyestercarbonates for controlled drug delivery. Part I. Tailoring the drug release. Polimery/Polymers 2013, 9, 654-662. [CrossRef]

34. Korsmeyer, R.W.; Gurny, R.; Doelker, E.; Buri, P.; Peppas, N.A. Mechanisms of solute release from porous hydrophilic polymers. Int. J. Pharm. 1983, 15, 25-35. [CrossRef]

35. Crank, J.; Gupta, R.S. Isotherm Migration Method in two dimensions. Int. J. Heat Mass Transf. 1975, 18, 1101-1107. [CrossRef]

36. Georgiadis, M.C.; Kostoglou, M. On the optimization of drug release from multi-laminated polymer matrix devices. J. Control. Release 2001, 77, 273-285. [CrossRef]

(C) 2020 by the authors. Licensee MDPI, Basel, Switzerland. This article is an open access article distributed under the terms and conditions of the Creative Commons Attribution (CC BY) license (http://creativecommons.org/licenses/by/4.0/). 